\title{
MÉXICO: ESTIMACIÓN DE LA MIGRACIÓN INTERNACIONAL EN EL PERÍODO 1960-1980
}

\author{
Por \\ Jorge Castro Martignoni*
}

\section{RESUMEN}

En este trabajo se presenta una estimación sobre el número de inmigrantes, emigrantes y migrantes netos internacionales por sexo y grupos de edades, para cada uno de los cuatro intervalos quinquenales de migración contenidos en el período que va de 1960 a 1980.

Se describe de la forma más acabada posible, el procedimiento empleado en la estimación de los migrantes internacionales de entrada y de salida, para los períodos de migración 1960-1965, 1965-1970, 1970-1975 y 1975-1980, concluyendo con la presentación de las estimaciones resultantes.

En el caso de la emigración, las fuentes de datos utilizadas fueron fundamentalmente el Censo de Población de Estados Unidos de 1980 a través de las estimaciones de Warren y Passel y la información derivada del proyecto de Investigación de la Migración Internacional de Latinoamérica (IMILA) llevado a cabo por el Centro Latinoamericano de Demografía (CELADE). La fuente de datos principal para la estimación de la inmigración internacional fue el Censo General de Población y Vivienda de 1980 de la república mexicana.

El hecho de tener que recurrir a fuentes de datos diferentes para la estimación de cada una de las dos componentes de la migración internacional, requiere de un cuidadoso tratamiento de los datos básicos, sin el cual se llegaría a resultados que contendrían importantes limitaciones producto de la falta de comparabilidad estricta entre las fuentes de información utilizadas. En este sentido, el trabajo pone especial cuidado en el tratamiento de las estimaciones de inmigrantes internacionales de retorno a México y emigrantes internacionales extranjeros.

\section{ABSTRACT}

This paper presents an estimation on the number of immigrants, emigrants and the net international migrants by nationality, sex and age groups for each of the fourth quinquennial intervals of migration contained in the period of 1960 to 1980.

It also describes in the most accurate possible way the procedure used to estimate the arrival and departure of international migrants for the periods of $1960-65,1965-70,1970-75$, and 1975-80, ending with the presentation of the resulting evaluations.

In the case of the emigration, the data sources used were fundamentaly the Population Census of the United States of 1980 using the Warren and Passel's estimation, derived from the investigation proyect for the international migration

* Subdirector de Programación de CONAPO. 
of Latin America (imil.A) claborated by the Latin American Demography Center (CELADE) the main data source for the estimation of the international immigration was the 1980 General Population and Housing Census of the Mexican Republic.

The fact of having to turn to different data sources for the estimation of each one of the two components of the international migration, requires a careful treatment of the basic facts without which it would bring out results with important limitations produced by the lack of strict comparison among the information used. In this sense, this work takes special care on the treatment of the estimations of the international immigrants retuming to Mexico and the foreign international emigrants.

\section{INTRODUCCIÓN}

En el año 1989, en el Área de Análisis Demográfico de la Dirección General de Estudios de Población del Consejo Nacional de Población (CONAPO), se emprendió la tarea de preparar las proyecciones de población a nivel nacional, por sexo y edades, para cada uno de los años comprendidos en el período 1980-2025. Estas proyecciones se llevaron a cabo mediante el método de los componentes demográficos (Pujol, 1988) utilizando un paquete computacional elaborado en la Dirección de Investigación Demográfica.

Una de las principales etapas en la tarea de preparación de proyecciones de población por el método de los componentes es la determinación de la población que sirve de base para iniciar los cálculos hacia el futuro (Rincón, 1984). La determinación de esta población base requiere a su vez la realización de una conciliación demográfica, destinada a compatibilizar la dinámica demográfica de uno o más períodos intercensales, buscando la coherencia de los censos con las estimaciones de la mortalidad, la fecundidad y la migración intemacional. Esta tarea de compatibilización hace necesaria, entonces, la obtención de estimaciones confiables respecto a las tres variables demográficas para el período que abarca el ejercicio de conciliación censal.

En el caso de las proyecciones de población de México, y con respecto a la migración internacional, fue preciso contar con estimaciones del saldo neto migratorio por sexo y grupos de edades al final de cada uno de los cuatro intervalos quinquenales pertenecientes al período 1960-1980, dentro del cual se realizó la conciliación demográfica. Para ello se procedió a obtener estimaciones de inmigrantes y emigrantes internacionales sobrevivientes al final de cada periodo quinquenal de migración; posteriormente, la migración neta internacional se obtuvo como la suma algebraica de las anteriores estimaciones. 
Dentro de los primeros meses de 1990 nos dedicamos a la tarea de revisar en forma exhaustiva aquellas estimaciones. Como resultado de este trabajo, para el que se ha considerado información adicional y en algunas partes se ha variado el procedimiento utilizado anteriormente, se obtuvicron nuevas cifras de entradas y salidas del país para cada uno de los cuatro períodos quinquenales de referencia.

Las cifras de migrantes netos por sexo y grupos de edades, para cada uno de los cuatro quinquenios incluidos en el intervalo de conciliación censal, resultan de un trabajo laborioso de estimación de inmigrantes y emigrantes internacionales. El objetivo fundamental de este documento consiste en realizar una exposición detallada de la metodología utilizada para la obtención de las estimaciones, así como la presentación de los resultados finales.

En primer término, se hacen algunos comentarios sobre las diferentes fuentes de datos utilizadas y los problemas de comparabilidad que ello ocasiona. Posteriormente se presenta la metodología seguida para la obtención de las estimaciones de inmigrantes y emigrantes internacionales. Finalmente, en la última parte del documento, en el apartado "consideraciones finales", se hace referencia a dos aspectos interesantes que ponen de manifiesto los resultados obtenidos, así como también algunos comentarios respecto al tipo de migrantes que se toman en cuenta en el procedimiento de estimación empleado.

\section{FUENTES DE DATOS Y TRATAMIENTO DE LA INFORMACIÓN BÁSICA}

En los países de América Latina existen dos tipos de fuentes mediante las cuales se puede obtener información para realizar estimaciones de la migración internacional: los registros administrativos y los censos o encuestas.

Las estimaciones de migrantes internacionales por quinquenio, que resultan del trabajo que aquí se presenta, tienen como insumos básicos la información contenida al respecto en los censos de población de México y Estados Unidos de 1980, y los datos recopilados a través del proyecto IMILA (CELADE, 1989) correspondientes a censos de población levantados alrededor de 1980.

En relación con las estimaciones de emigrantes internacionales, más del $98.5 \%$ del volumen total sobreviviente en 1980 corresponde a personas residentes en Estados Unidos. Se puede apreciar así que la fuente de datos principal para la estimación de este componente de la migración internacional fue el censo de población estadounidense de 1980, esencialmente a 
través de las estimaciones de Warren y Passel (1987), las cuales corresponden a una corrección de las cifras de mexicanos residentes en Estados Uniđos según el mencionado levantamiento censal. Por su parte, las estimaciones referidas a la inmigración internacional, tuvieron como fuente de información fundamental, los datos incluidos en los tabulados 36 a 40 del volumen n del Resumen General del Censo de Población àe 1980, así como también información censal inédita.

El hecho de tener que recurrir a datos provenientes del censo de población de Estados Unidos como fuente de información principal para la estimación de la emigración intemacional, obedece a que en general en los censos o encuestas no se incluye alguna pregunta destinada específicamente a cuantificar el volumen de este componente. En la última década, la Unión Internacional para el Estudio Científico de la Población y el CELADE han venido desarrollando y utilizando algunas técnicas de estimación de la emigración internacional, basadas en información proveniente de preguntas censales que indagan sobre la residencia de parientes (Somoza, 1977; Hill, 1979; Zaba, 1986). Este tipo de preguntas fueron incluidas en los cuestionarios de censos de población de los años ochenta de unos pocos países latinoamericanos, dentro de los cuales México no se encuentra; desafortunadamente, la boleta del último levantamiento censal mexicano llevado a cabo el mes de marzo de 1990, tampoco contiene ninguna de aquellas preguntas.

Por otra parte, es conveniente recordar que las estimaciones de emigrantes internacionales, que se deducen de datos censales de los países de destino, generalmente contienen limitaciones que no es posible evadir: el hecho de que en los censos no siempre se enumera a todas las personas nacidas en el extranjero como tales; problemas de subenumeración relacionados a la omisión censal; aspectos relativos al tipo de censo que se llevó a cabo, "de jure" o "de facto"; el hecho de que no todos los países levantan sus censos en la misma fecha, etc. (Jaspers, 1987).

Como se mencionó, casi el 99\% de la emigración internacional mexicana se dirige a Estados Unidos, por lo cual la inmensa mayoría de los datos relativos a emigrantes mexicanos provienen de una fuente única de información como lo es el censo de población estadounidense, levantado el 1o. de abril de 1980. Esta ventaja, que de por sí ya es muy importante, se vio acrecentada puesto que no se tomó directamente la información censal, sino que se trabajó con las estimaciones de Warren y Passel, que son estimaciones obtenidas luego de realizar correcciones por omisión a las cifras censales.

A pesar de lo anterior, y en vista de que las principales fuentes de información para la estimación de la migración internacional mexicana son el censo de población de México y de Estados Unidos de 1980, no es 
posible soslayar algunos aspectos relativos a la comparabilidad de la información tomada de ambos levantamientos censales, a riesgo de llegar a obtener estimaciones que no cuantificarian de forma más o menos confiable el número de movimientos de entrada y de salida ocurridos dentro de cada período quinquenal de migración.

En primer término, debe mencionarse que tanto el censo de México como el de Estados Unidos son censos de derecho, "de jure", en los cuales se enumera a toda persona que reside habitualmente dentro del territorio nacional. En lo que respecta a la migración internacional, el censo de Estados Unidos nos provee de información en relación a dos tipos de inmigrantes procedentes de México (emigrantes, desde el punto de vista del país de origen): mexicanos residentes en Estados Unidos en 1980 (migrantes de toda la vida), clasificados por período de llegada, ${ }^{1}$ y no mexicanos residentes en aquel país en ese año, que residían en México cinco años atrás (emigrantes extranjeros del período 1975-1980). ${ }^{2}$ Del censo de población mexicano se obtiene el número de personas que han residido más de seis meses fuera del estado o entidad federativa de empadronamiento, ${ }^{3}$ y cuyo lugar de residencia anterior al actual era un país extranjero (inmigrantes internacionales). Dentro de este grupo de individuos se pueden identificar también dos tipos de inmigrantes: los extranjeros provenientes del exterior y los mexicanos que regresan luego de haber emigrado previamente (migrantes de retorno). ${ }^{4}$

La identificación de las distintas categorías de migrantes sobre los cuales podemos obtener información al considerar las dos fuentes de datos indicados, aunada a la intención de obtener estimaciones de la migración neta internacional - $y$ de sus componentes - para períodos acotados (intervalos quinquenales), nos coloca ante la necesidad ineludible de tener que dar un tratamiento especial a los datos referidos a dos de los cuatro tipos mencionados de migrantes intemacionales: los emigrantes extranjeros y los migrantes de retorno.

Los emigrantes extranjeros son individuos no mexicanos que luego de haber estado residiendo durante cierto tiempo en la república mexicana,

1 En el censo de población de Estados Unidos de 1980 se realizó la pregunta cerrada: ¿cuándo entró esta persona a los Estados Unidos para permanecer en el país?

2 En el censo de población de Estados Unidos de 1980 se realizó la pregunta: ¿dónde vivía esta persona cinco años atrás (el lo de abril de 1975)?

"Lugar de residencia". Se trata de saber si esta persona ha estado fuera por más de 6 meses de este estado o entidad federativa. Los cambios de residencia dentro de un mismo estado, no cuentan. Si la respuesta a la primera pregunta es no, se pasa al siguiente tema. Si la respuesta es afirmativa, se hace la segunda pregunta".

4 Del total de personas que declaró que su lugar de residencia anterior al actual era un país extranjero, aproximadamente el $48 \%$ eran mexicanos migrantes de retomo. (DGE, s/f:52), 
emigraron del país para pasar a vivir en otro diferente. Las estimaciones para el período 1975-1980 se derivaron directamente del censo de población de Estados Unidos de $1980^{5}$ (Partida, 1990). Para los otros tres períodos quinquenales de migración se obtuvieron estimaciones en forma retrospectiva, a partir de la población nacida en el exterior enumerada en el censo mexicano de aquel año, De esta forma se logra contabilizar las salidas del país (emigración) de estos migrantes extranjeros. Pero para poder obtener estimaciones coherentes de la migración internacional, no es posible dejar de tomar en cuenta también, dentro de las estimaciones de inmigrantes internacionales, el movimiento de entrada que precede a aquél de salida y que deberá considerarse dentro del intervalo de migración correspondiente.

Con una situación similar nos enfrentamos al trabajar con los migrantes mexicanos de retorno que suponemos provenientes todos de Estados Unidos. Como ya se ha dicho, las estimaciones de Warren y Passel corresponden a mexicanos residentes en Estados Unidos en 1980, clasificados de acuerdo con su período de llegada. En estas estímaciones por tanto, no están contemplados los mexicanos que emigraron hacia Estados Unidos en algún momento del intervalo 1960-1980, y permanecieron en aquel país por lo menos seis meses para regresar a México precisamente antes del levantamiento del censo norteamericano de 1980, siendo captados por el censo mexicano de ese año (migrantes de retorno). Sin embargo, existen en las estimaciones de migrantes internacionales, puesto que son personas enumeradas por el censo de México, que han residido más de seis meses fuera de su lugar actual y cuyo lugar de residencia inmediato anterior fue un país extranjero. Es por demás claro el error en que se incurriría si para la obtención de las estimaciones de migrantes internacionales nos limitáramos a tomar la información tal como surge de los tabulados censales sin darle ningún tratamiento especial. $\mathrm{Si}$ se procediera así, se estaría considerando la entrada al país (inmigración) de los migrantes de retorno mexicanos que habían emigrado previamente a Estados Unidos, pero no su salida (emigración); y por ende, los saldos migratorios calculados para cada período estarían equivocados. Se hace necesario, entonces, realizar estimaciones relativas al momento en que se produjo la salida del país de los migrantes de retorno, las cuales deberán ser tomadas en cuenta para la estimación de la emigración internacional de cada período quinquenal de interés. Pero este procedimiento de ubicación de las salidas de los migrantes mexicanos de retorno dentro de cada

5 Dado ello, se va a asumir el supuesto de que la emigración de extranjeros del período 1975-1980 tuvo como único pás de destino a los Estados Unidos. 
intervalo de migración, debe ser por demás cuidadoso, puesto que no se pueden pasar por alto las características especiales de la emigración mexicana hacia Estados Unidos.

Reiteradamente se ha manifestado en diversas investigaciones relativas a la emigración mexicana hacia aquel país, que la mayor parte de ésta es laboral, indocumentada y temporal. ${ }^{6}$ En virtud de ello, parece bastante obvio admitir que una parte importante de las personas que regresan de los Estados Unidos, en un lustro determinado, son individuos que emigraron hacia allá dentro del mismo intervalo. El problema en cuestión es, por lo tanto, la adopción de un procedimiento de trabajo relativo a los migrantes de retorno que, atendiendo fundamentalmente al carácter temporal de la emigración mexicana hacia Estados Unidos, nos permita, por una parte, cuantificar el número de migrantes de retorno que emigraron previamente dentro del mismo período quinquenal en que se produjo su regreso; y por otra, ubicar la salida de los migrantes de retorno, que emigraron previamente en lustros diferentes al de regreso, en los respectivos intervalos de migración. Posteriormente, los movimientos de salida de cada lustro correspondientes a aquellos migrantes, deberán ser tenidos en cuenta en la estimación de la emigración internacional de los diferentes períodos.

6 "Es una migración laboral. De acuerdo con las investigaciones mexicanas y norteamericanas, casi todos los migrantes son hombres jóvenes, con un bajo nivel de educación y sin conocimiento del inglés, solos (no viajan con sus familias), la mayorís provenientes de regiones rurales de México y que van a Estados Unidos a buscar un empleo.

Es una migración temporal o estacional. Esto significa que no se trata de migrantes permanentes; son personas que quieren un empleo y no quedarse a vivir en Estados Unidos, La mayoría de los trabajadores mexicanos en Estados Unidos carece de documentos migratorios en orden." (Morales, 1989:18).

"El tiempo de permanencia de los trabajadores migratorios indocumentados, en promedio, es de seis meses; aunque éste puede variar desde algunos días hasta más de un año. Los mexicanos tienen una preferencia por vivir en México, debido a la cercanía geográfica y al hecho de que sus empleos en el país vecino del norte, incluso muchos no agrícolas, son estacionales. En cambio, los indocumentados que residen habitualmente en Estados Unidos tienden a establecerse por varios años". (García y Griego y Verea, 1988:85).

"Ya hemos señalado que la característica de temporalidad de la migración internacional mexicana le da un giro que requiere una explicación diferente a la de la inmigración permanente o de largo plazo que es la que más ha sido estudiada a nivel mundial. Esta característica de temporalidad está intimamente ligada a la noción de que la migración laboral mexicana a Estados Unidos ha ocurrido en el contex to de un sistema económico que rebasa la frontera entre los dos países, cuyo diseño responde básicamente a intereses situados en aquel país" (Martínez y Bustamante, 1978:17).

"El panorama que surge de nuestra información viene a confirmar aún más una de las características más sobresalientes de la migración mexicana al país vecinodel norte: movimientos con características de temporalidad bastante acentuadas. El promedio de estancia de la población W (migrantes de retomo) fue cerca de 160 días, o sea, ligeramente superior a 5 meses. Sin embargo, 7 de cada 10 migrantes pernaneció en Estados Unidos menos de 6 meses múentras que, en el otro extremo, cerca del $13 \%$ tuvieron una permanencia superior al año (el $7.3 \%$ estuvo entre uno $\mathrm{y}$ dos años y el 5.5\% permaneció tres años o más)" (Zazueta, 1980:17). 
Para finalizar este punto, por demás relevante dentro del procedimiento de estimación, sería conveniente realizar algunas precisiones adicionales:

Primero: la necesidad de dar un tratamiento especial a los datos sobre emigrantes extranjeros y migrantes de retorno se debe a dos aspectos fundamentales: a) el hecho de tener que recurrir para la estimación de la emigración internacional a una fuente de información externa como lo es el censo de población estadounidense; y b) el propósito de obtener estimaciones de la migración internacional para períodos quinquenales. Por otra parte, con relación a esto último, si el objetivo hubiera sido la obtención de estimaciones de migrantes de toda la vida sobrevivientes en 1980, el problema de ubicar la entrada y salida de los emigrantes extranjeros y los migrantes de retorno respectivamente, no se presentaría.

Segundo: las cifras de inmigrantes y emigrantes internacionales que se presentan en este trabajo pretenden aproximarse al número de movimientos de entrada y de salida ocurridos dentro de cada intervalo de migración de referencia, calculados a partir de los migrantes sobrevivientes al final de cada período. Es por esta razón que se optó por considerar, en las estimaciones de emigrantes de cada lustro, la salida de los migrantes mexicanos de retorno que habían emigrado previamente dentro del mismo quinquenio en que regresaron a México. ${ }^{8}$

Tercero: no debe perderse de vista que las estimaciones de inmigrantes y emigrantes que resultan de este trabajo están en cierta medida subestimando el verdadero número de entradas y salidas ocurridas dentro de cada intervalo de migración (Naciones Unidas, 1972). Este problema es inevitable, toda vez que, como ésta, se mida la migración de un período en base a la información sobre el últumo movimiento realizado, ${ }^{9}$ De alguna manera esta limitante fue parcialmente superada al tomar en cuenta, en las estimaciones de emigrantes de cada período, la entrada y la salida previa de los emigrantes extranjeros y los migrantes de retorno, respectivamente.

8 Otra posibilidad hubiera sido no considerar ni la salida ni la entrada de estos migrantes de retomo. Esta alternativa de trabajo no afectaria la estimación del saldo neto migratorio del periodo, pero estaría subestimando, en igual medida, el número de movimientos de entrada y de salida que se produjeron dentro de ese intervalo.

9 Un individuo mexicano que, por ejemplo, llegó al país dentro del quinquenio inmediato anterior al censo y que posteriomente, en el mismo período quinquenal, cambi6 de lugar de residencia dentro del territorio nacional, será computado como migrante intemo y no como migrante internacional. 


\section{ESTIMACIÓN DE LA INMIGRACIÓN INTERNACIONAL}

El procedimiento de estimación de la inmigración comenzó a partir de las cifras contenidas en los cuadros 37,39 y 40 del Resumen General del Censo de Población de México de 1980. De dichos tabulados se pudo derivar información respecto a:

- la población total residente en México en 1980, clasificada por tiempo de residencia en la entidad federativa de empadronamiento, según sexo y grupos de edades (cuadro 1);

- la población que cambió de lugar de residencia, clasificada de acuerdo al tiempo de residencia en su lugar de empadronamiento, el lugar de residencia anterio: y el sexo (cuadro 2); y

- la población que cambió de lugar de residencia, clasificada esta vez de acuerdo al lugar de residencia anterior, según sexo y grupos de edades (cuadro 3 ).

Conjugando la información incluida en los tres primeros cuadros, es posible hacer un nuevo tabulado análogo al cuadro 2 , pero enriquecido por los datos sobre distribución por edades que contienen los dos restantes. En este nuevo cuadro (cuadro 4) se clasifica a la población que cambió de lugar de residencia, por tiempo de residencia en la entidad federativa de empadronamiento, según lugar de residencia anterior, sexo y grupos de edades; en él se pueden apreciar con claridad algunas limitantes de la información básica que, a efectos de los requerimientos de este trabajo, es preciso dar solución. Por ejemplo:

a) La existencia de dos rubros de "no especificado"; uno relativo a la clasificación por tiempo de residencia en la entidad de empadronamiento, dentro del cual se encuentra casi el $10 \%$ de la población total que cambió de lugar de residencia (440,120 hombres y 454,288 mujeres), y otro referido al lugar de residencia anterior (ver conclusión del cuadro 4), en el que está contenido poco menos del 13\% del total de migrantes $(569,534$ hombres y 594,934 mujeres);

b) el hecho de no contar con las distribuciones por grupos de edades para los totales de población de cada sexo clasificados por tiempo de residencia en la entidad de empadronamiento, y cuyo lugar de residencia anterior era: otra entidad federativa (migrantes internos), un país extranjero (inmigrantes internacionales), o no se encontraba especificado;

c) la falta de distribuciones por grupos de edades que se prolonguen hasta el grupo abierto final " 85 o más" para los migrantes totales clasificados según lugar de residencia anterior; $y$ 
CUADRO 1. México: población total por tiempo de residencia en la entidad federativa de empadronamiento, según sexo y grupos quinquenales de edades, año 1980.

\begin{tabular}{|c|c|c|c|c|c|c|c|c|}
\hline \multirow{2}{*}{$\begin{array}{l}\text { Sexo y } \\
\text { grupos de } \\
\text { edades }\end{array}$} & \multirow{2}{*}{ Total } & \multicolumn{6}{|c|}{ Tiempo de residencia en la entidad federativa de empadronamiento } & \multirow{2}{*}{$\begin{array}{l}\text { Condición } \\
\text { migratoria no } \\
\text { especificada }\end{array}$} \\
\hline & & Siempre & Total & $\begin{array}{c}\text { Menos de } \\
5 \text { años }\end{array}$ & $\begin{array}{l}5 \text { a } 9 \\
\text { años }\end{array}$ & $\begin{array}{l}10 \text { o más } \\
\text { años }\end{array}$ & $\begin{array}{l}\text { no espe- } \\
\text { cificado }\end{array}$ & \\
\hline Total & 66846833 & 51988532 & 8979892 & 2986947 & 1641968 & 3456569 & 894408 & 5878409 \\
\hline Total hombres & 33039307 & 25706119 & 4447854 & 1519598 & 814065 & 1674071 & 440120 & 2885334 \\
\hline $0-4$ & 4698512 & 3850333 & 188081 & 156983 & & & 31098 & 660098 \\
\hline $5-9$ & 5172923 & 4316128 & 332834 & 181339 & 104860 & & 46635 & 523961 \\
\hline $10-14$ & 4574675 & 3807192 & 368810 & 134602 & 111961 & 78018 & 44229 & 398673 \\
\hline $15-19$ & 3766688 & 3028246 & 450102 & 175917 & 86544 & 134687 & 52954 & 288340 \\
\hline $20-24$ & 2972174 & 2219485 & 543395 & 236872 & 96903 & 148778 & 60842 & 209294 \\
\hline $25-29$ & 2325060 & 1672397 & 501773 & 197454 & 102926 & 154539 & 46854 & 150890 \\
\hline $30-34$ & 1885628 & 1337445 & 433489 & 141495 & 88112 & 168405 & 35477 & 114694 \\
\hline $35-39$ & 1664573 & 1190783 & 373865 & 96588 & 71108 & 176787 & 29382 & 99925 \\
\hline $40-44$ & 1359706 & 978430 & 300848 & 62469 & 48745 & 166726 & 22908 & 80428 \\
\hline $45-49$ & 1134689 & 821453 & 245844 & 43258 & 33750 & 150485 & 18351 & 67392 \\
\hline $50-54$ & 912884 & 661097 & 197415 & 29703 & 23320 & 130180 & 14212 & 54372 \\
\hline $55-59$ & 732503 & 529230 & 159779 & 21148 & 16420 & 110716 & 11495 & 43494 \\
\hline $60-64$ & 541862 & 396170 & 110767 & 14132 & 10324 & 78421 & 7890 & 34925 \\
\hline 65 o más & 1204676 & 883497 & 239771 & 27248 & 18949 & 175953 & 17621 & 81408 \\
\hline No especificado & 92754 & 14233 & 1081 & 390 & 143 & 376 & 172 & 77440 \\
\hline
\end{tabular}


CUADRO 1. (continuación).

\begin{tabular}{|c|c|c|c|c|c|c|c|c|}
\hline $\begin{array}{l}\text { Sexo y } \\
\text { grupos de } \\
\text { edades }\end{array}$ & Total & $\begin{array}{l}\text { Tien } \\
\text { Siempre }\end{array}$ & $\begin{array}{l}\text { o de residen } \\
\text { Total }\end{array}$ & $\begin{array}{l}\text { a en la entid: } \\
\text { Menos de } \\
5 \text { años }\end{array}$ & $\begin{array}{l}\text { ederativa d } \\
5 \text { a } 9 \\
\text { años }\end{array}$ & $\begin{array}{l}\text { empadronam } \\
10 \text { o más } \\
\text { años }\end{array}$ & $\begin{array}{l}\text { No espe- } \\
\text { cificado }\end{array}$ & $\begin{array}{l}\text { Condición } \\
\text { migratoria no } \\
\text { especificada }\end{array}$ \\
\hline Total mujeres & 33807526 & 26282413 & 4532038 & 1467349 & 827903 & 1782498 & 454288 & 2993075 \\
\hline $0-4$ & 4649356 & 3814096 & 185162 & 154813 & & & 30349 & 650098 \\
\hline $5-9$ & 5111032 & 4263505 & 329195 & 179695 & 103498 & & 46002 & 518332 \\
\hline $10-14$ & 4519676 & 3744738 & 383015 & 148878 & 111397 & 76963 & 45777 & 391923 \\
\hline $15-19$ & 3889851 & 3076515 & 516692 & 229077 & 96394 & 134872 & 56349 & 296644 \\
\hline $20-24$ & 3182353 & 2379064 & 576839 & 240516 & 121075 & 155548 & 59700 & 226450 \\
\hline $25-29$ & 2479332 & 1801056 & 509307 & 170298 & 114793 & 176375 & 47841 & 168969 \\
\hline $30-34$ & 1952431 & 1408907 & 416160 & 106381 & 85087 & 188152 & 36540 & 127364 \\
\hline $35-39$ & 1742361 & 1274270 & 353926 & 68813 & 61518 & 193986 & 29609 & 114165 \\
\hline $40-44$ & 1385492 & 1017469 & 278449 & 43006 & 39751 & 173352 & 22340 & 89574 \\
\hline $45-49$ & 1180940 & 868790 & 235170 & 31158 & 27912 & 157417 & 18683 & 76980 \\
\hline $50-54$ & 951079 & 695703 & 193202 & 24240 & 19591 & 133993 & 15378 & 62174 \\
\hline $55-59$ & 733400 & 531639 & 153848 & 19025 & 14326 & 108284 & 12213 & 47913 \\
\hline $60-64$ & 573284 & 416834 & 116494 & 14901 & 10295 & 81658 & 9640 & 39956 \\
\hline 65 o más & 1356444 & 974920 & 283420 & 36125 & 22114 & 201469 & 23712 & 98104 \\
\hline No especificado & 100495 & 14907 & 1159 & 423 & 152 & 429 & 155 & 84429 \\
\hline
\end{tabular}

FUENTE: x Censo General de Población y Vivienda, 1980, Resumen General, Vol. II, cuadro 37. 1986. INEGI. 
CUADRO 2. México: población que cambió de lugar de residencia por tiempo de residencia en la entidad federativa de empadronamiento, según lugar de residencia anterior y sexo (1980).

\begin{tabular}{|c|c|c|c|c|c|c|}
\hline \multirow{2}{*}{$\begin{array}{l}\text { Lugar de } \\
\text { residencia } \\
\text { anterior y } \\
\text { sexo }\end{array}$} & \multirow[t]{2}{*}{ Total } & \multicolumn{5}{|c|}{$\begin{array}{l}\text { Tiempo de residencia en la entidad } \\
\text { federativa de empadronamiento }\end{array}$} \\
\hline & & $\begin{array}{l}\text { Menos } \\
\text { de } 1 \text { año }\end{array}$ & $\begin{array}{l}1 \text { a } 4 \\
\text { años }\end{array}$ & $\begin{array}{l}5 \text { a } 9 \\
\text { años }\end{array}$ & $\begin{array}{l}10 \text { o más } \\
\text { años }\end{array}$ & $\begin{array}{l}\text { no espe- } \\
\text { cificado }\end{array}$ \\
\hline Total migrantes & 8979892 & 897375 & 2089572 & 1641968 & 3456569 & 894408 \\
\hline Hombres & 4447854 & 464914 & 1054684 & 814065 & 1674071 & 440120 \\
\hline Mujeres & 4532038 & 432461 & 1034888 & 827903 & 1782498 & 454288 \\
\hline \multicolumn{7}{|l|}{ Entidades } \\
\hline federativas & 7291865 & 670562 & 1688651 & 1353292 & 2759867 & 819493 \\
\hline Hombres & 3551466 & 332171 & 840146 & 666006 & 1323493 & 389650 \\
\hline Mujeres & 3740399 & 338391 & 848505 & 687286 & 1436374 & 429843 \\
\hline \multicolumn{7}{|l|}{ Paises } \\
\hline extranjeros & 523559 & 104691 & 140684 & 71331 & 131938 & 74915 \\
\hline Hombres & 326854 & 70540 & 85008 & 41171 & 79665 & 50470 \\
\hline Mujeres & 196705 & 34151 & 55676 & 30160 & 52273 & 24445 \\
\hline No especificado & 1164468 & 122122 & 260237 & 217345 & 564764 & 0 \\
\hline Hombres & 569534 & 62203 & 129530 & 106888 & 270913 & 0 \\
\hline Mujeres & 594934 & 59919 & 130707 & 110457 & 293851 & 0 \\
\hline
\end{tabular}

FUENIE: X Censo General de Población y Vivienda, 1980, Resumen General, Vol, II, Cuadro 39. INEGI.

d) la carencia de categorías dentro de la clasificación por tiempo de residencia, a partir de las cuales se pudieran deducir directamente los migrantes de los intervalos 1960-1965 y 1965-1970.

El primer paso en el procedimiento de estimación correspondió entonces a la distribución de los rubros "no especificado" señalados anteriormente, comenzando por distribuir la columna y luego la fila.

La distribución de la categoría "no especificado", correspondiente al tiempo de residencia en la entidad de empadronamiento (columna), se hizo en dos partes. En primera instancia se distribuyó, para cada sexo por separado, el total de población migrante de cada grupo de edades incluido en aquel rubro. La distribución se realizó en forma proporcional en función de las cifras de población del cuadro 4 , indicadas en cada categoría de 
CUADRO 3. México: población que cambió de lugar de residencia, por lugar de residencia anterior, según sexo y grupos quinquenales de edad (1980).

\begin{tabular}{|c|c|c|c|c|}
\hline \multirow{2}{*}{$\begin{array}{l}\text { Sexo y } \\
\text { grupos de } \\
\text { edades }\end{array}$} & \multirow[t]{2}{*}{ Total } & \multicolumn{3}{|c|}{ Lugar de residencia anterior } \\
\hline & & $\begin{array}{l}\text { Entidades } \\
\text { federativas }\end{array}$ & $\begin{array}{c}\text { País } \\
\text { extranjero }\end{array}$ & $\begin{array}{c}\text { No } \\
\text { especificado }\end{array}$ \\
\hline Totul & 8979892 & 7291865 & 523559 & 1164468 \\
\hline Total hombres & 4447854 & 3551466 & 326854 & 569534 \\
\hline $0-4$ & 188081 & 139584 & 9896 & 38601 \\
\hline $5-9$ & 332834 & 271805 & 13906 & 47123 \\
\hline $10-14$ & 368810 & 307012 & 11598 & 50200 \\
\hline $15-19$ & 450102 & 368853 & 24188 & 57061 \\
\hline $20-24$ & 543395 & 432440 & 45264 & 65691 \\
\hline $25-29$ & 501773 & 402155 & 40648 & 58970 \\
\hline $30-34$ & 433489 & 349171 & 34431 & 49887 \\
\hline $35-39$ & 373865 & 299657 & 30082 & 44126 \\
\hline $40-44$ & 300848 & 239476 & 25282 & 36090 \\
\hline $45-49$ & 245844 & 193955 & 21770 & 30119 \\
\hline $50-54$ & 197415 & 154906 & 18268 & 24241 \\
\hline $55-59$ & 159779 & 124675 & 15249 & 19855 \\
\hline $60-64$ & 110767 & 85784 & 10468 & 14515 \\
\hline 65 o más & 240852 & 181993 & 25804 & 33055 \\
\hline Total mujeres & 4532038 & 3740399 & 196705 & 594934 \\
\hline $0-4$ & 185162 & 137243 & 9733 & 38186 \\
\hline $5-9$ & 329195 & 269206 & 13708 & 46281 \\
\hline $10-14$ & 383015 & 319264 & 11904 & 51847 \\
\hline $15-19$ & 516692 & 432397 & 18306 & 65989 \\
\hline $20-24$ & 576839 & 479893 & 25940 & 71006 \\
\hline $25-29$ & 509307 & 424333 & 23927 & 61047 \\
\hline $30-34$ & 416160 & 347589 & 19513 & 49058 \\
\hline $35-39$ & 353926 & 295866 & 14144 & 43916 \\
\hline $40-44$ & 278449 & 232761 & 10524 & 35164 \\
\hline $45-49$ & 235170 & 195370 & 8769 & 31031 \\
\hline $50-54$ & 193202 & 158713 & 9060 & 25429 \\
\hline $55-59$ & 153848 & 126005 & 7879 & 19964 \\
\hline $60-64$ & 116494 & 94245 & 6545 & 15704 \\
\hline 65 o más & 284579 & 227514 & 16753 & 40312 \\
\hline
\end{tabular}

FUENTE: $x$ Censo General de Población y Vivienda, 1980, Resumen General, Vol. II, Cuadro 40. INEGI. 1986. 
tiempo de residencia en el grupo de edades correspondiente. Luego, fue preciso distribuir las cifras totales de cada sexo clasificadas por tiempo de residencia, obtenidas en la etapa previa, según lugar de residencia anterior (entidad federativa o país extranjero); para ello se utilizó la téenica iterativa de eliminación de la diferencia por aproximaciones sucesivas (Naciones Unidas, 1975). Este procedimiento - mejor conocido como "tabla cuadrada"- se aplicó por sexo, tomando como marginales verticales (T.j), las cantidades obtenidas en la primera parte y, como marginales horizontales (Ti.) las cifras provenientes đe la clasificación según lugar de residencia anterior y sexo de la columna "no especificado" del cuadro 2. El arreglo inicial de dos filas por tres columnas del cual se partió para la aplicación de la técnica, resultó de distribuir los marginales horizontales por tiempo de residencia, en forma proporcional, de acuerdo a las cifras contenidas en el mencionado cuadro.

La distribución del rubro "no especificado" correspondiente a la clasificación respecto al lugar de residencia anterior (fila), se realizó en forma análoga a la anterior. En princípio se distribuyeron según lugar de residencia anterior, en forma proporcional, los montos de población de cada sexo y grupo de edades pertenecientes a la categoría "no especificado"; esta distribución se hizo en función de las cantidades indicadas en cada una de las categorías de lugar de residencia anterior, en el grupo de edades correspondiente. Posteriormente, las cantidades totales de cada sexo clasificadas según lugar de residencia anterior (entidad federativa o país extranjero) obtenidas en la etapa precedente, se distribuyeron por tiempo de residencia, recurriéndose nuevamente al procedimiento de la "Tabla cuadrada". En esta ocasión se tomaron como marginales horizontales (Ti.) las cifras deducidas en la primera parte de la distribución, y como marginales verticales (T.j.), el número de efectivos contenidos en cada categoría de la clasilicación por tiempo de residencia de la fila de "no especificado"; el arreglo inicial de dos filas por tres columnas resultó de distribuir los marginales verticales según lugar de residencia anterior, en forma proporcional, de acuerdo a las cantidades del cuadro 2.

La etapa siguiente consistió en estimar las distribuciones por edad. Para ello, se comenzó por calcular en función de los datos del cuadro 3, las distribuciones relativas de cada sexo según grupos de edades del total de migrantes (internos e internacionales), de los migrantes internos y de los inmigrantes internacionales. La comparación por sexo de las respectivas distribuciones (ver figuras 1 y 2 ), reveló que las correspondientes al total de migrantes y migrantes internos eran muy coincidentes, siendo en cambio significativamente diferentes a los patrones mostrados por las distribuciones de los inmigrantes internacionales, ${ }^{10}$ En virtud de esto, 
se aceptó que, para cada sexo, la distribución relativa por tiempo de residencia correspondiente al número de efectivos en cada grupo de edades de la población cuyo lugar de residencia anterior había sido una entidad federativa (migrantes internos), era la misma que la observada en la población total que cambió de lugar de residencia (ver cuadro 1). En base a este supuesto se procedió a distribuir los respectivos montos de población, obteniéndose, de esta forma, una primera aproximación a la distribución por tiempo de residencia, del número de individuos migrantes internos de cada sexo y grupo de edades. La distribución análoga para la población proveniente de países extranjeros (inmigrantes internacionales), surgió de hacer la diferencia entre cada celda de las distribuciones del total de migrantes y la celda respectiva en las distribuciones estimadas para los migrantes internos. De esta forma, el número de efectivos estimado por sexo y grupo de edades, para cada categoria de tiempo de residencia y lugar de residencia anterior, reproduce correctamente cada marginal horizontal (primera columna del cuadro 4), asimismo las cifras en cada celda de la distribución por tícmpo de residencia según sexo y grupos de edades del total de migrantes; pero, en cambio, no concuerdan con los montos totales por tiempo de residencia según lugar de residencia anterior y sexo. La concordancia de las estimaciones de las celdas con los tres tipos de totales se logró empleando el procedimiento iterativo de eliminación de la diferencia mediante aproximaciones sucesivas. La técnica se aplicó a una matriz de tres dimensiones cuyo arreglo inicial estuvo conformado por las estimaciones descrilas anteriormente, $y$ los tres marginales con los cuales se cuadraron las cantidades de las celdas fueron las correspondientes a los totales del cuadro 4 , a saber:

- marginales horizontales (Ti...); clasificación de la población total que cambió de lugar de residencia según lugar de residencia anterior, sexo y grupos de edades;

- marginales verticales (T.j.): clasificación de la población total que cambió de lugar de residencia, por tiempo de residencia en la entidad de empadronamiento, según lugar de residencia anterior y sexo.

- marginales fondo (T..k): clasificación de la población total que cambió de lugar de residencia, por tiempó de residencia en la entidad de empadronamiento, según sexo y grupos de edades.

\footnotetext{
${ }^{10}$ El mismo ejercicio de compuración de las distribuciones relativas, se llevó a cabo luego de realizadas las correcciones producto de la distribución de los rubros de "noespecificado", las diferencias entre los niveles de las frecuencias relativas obtenidas en esta oportunidad y los calculados anterionmente no fueron de importancia, y por lo tanto, se observó nuevamente la coincidencia por sexo entre el patrón de distribución de los migrantes intemos y el total de migrantes.
} 
CUADRO 4. México: población que cambió de lugar de residencia, por tiempo de residencia en la entidad federativa de empadronamiento, según lugar de residencia anterior, sexo y grupos de edades (1980).

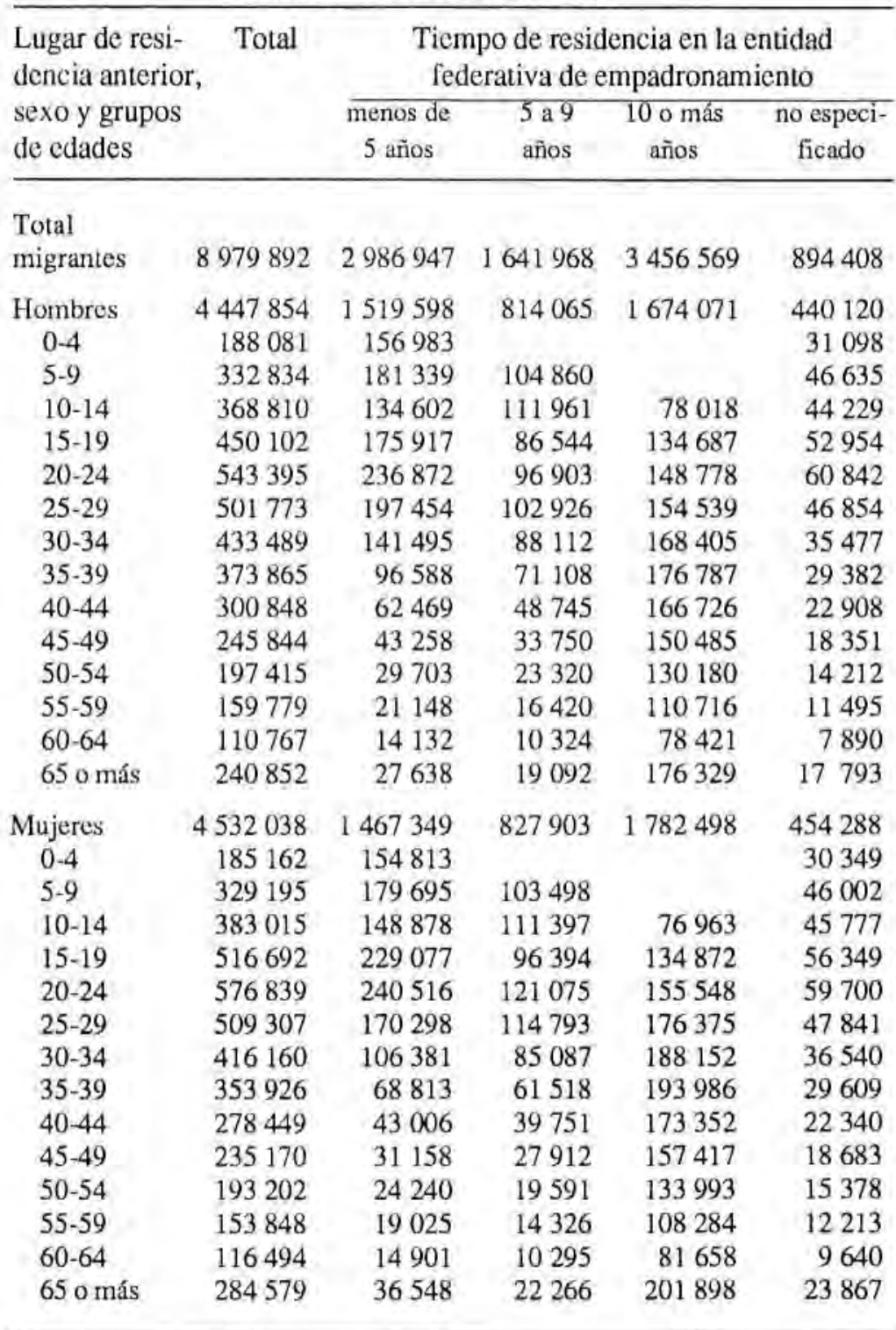


CUADRO 4. (Continuación).

\begin{tabular}{|c|c|c|c|c|c|}
\hline \multirow{2}{*}{$\begin{array}{l}\text { Lugar de resi- } \\
\text { dencia anterior, } \\
\text { sexo y grupos } \\
\text { de edades }\end{array}$} & \multirow{2}{*}{ Total } & \multicolumn{4}{|c|}{$\begin{array}{l}\text { Tiempo de residencia en la entidad } \\
\text { federativa de empadronamiento }\end{array}$} \\
\hline & & $\begin{array}{l}\text { menos de } \\
5 \text { años }\end{array}$ & $\begin{array}{l}5 \text { a } 9 \\
\text { años }\end{array}$ & $\begin{array}{l}10 \text { o más } \\
\text { años }\end{array}$ & $\begin{array}{l}\text { no especi- } \\
\text { ficado }\end{array}$ \\
\hline $\begin{array}{l}\text { Entidades } \\
\text { federativas }\end{array}$ & 7291865 & 2359213 & 1353292 & 2759867 & 819493 \\
\hline $\begin{array}{l}\text { Hombres } \\
0-4 \\
5-9 \\
10-14 \\
15-19 \\
20-24 \\
25-29 \\
30-34 \\
35-39 \\
40-44 \\
45-49 \\
50-54 \\
55-59 \\
60-64 \\
65 \text { o más }\end{array}$ & $\begin{array}{r}3551466 \\
139584 \\
271805 \\
307012 \\
368853 \\
432440 \\
402155 \\
349171 \\
299657 \\
239476 \\
193955 \\
154906 \\
124675 \\
85784 \\
181993\end{array}$ & 1172317 & 666006 & 1323493 & 389650 \\
\hline $\begin{array}{l}\text { Mujeres } \\
0-4 \\
5-9 \\
10-14 \\
15-19 \\
20-24 \\
25-29 \\
30-34 \\
35-39 \\
40-44 \\
45-49 \\
50-54 \\
55-59 \\
60-64 \\
65 \text { o más }\end{array}$ & $\begin{array}{r}3740399 \\
137243 \\
269206 \\
319264 \\
432397 \\
479893 \\
424333 \\
347589 \\
295866 \\
232761 \\
195370 \\
158713 \\
126005 \\
94245 \\
227514\end{array}$ & 1186896 & 687286 & 1436374 & 429843 \\
\hline
\end{tabular}


CUADRO 4. (Continuación).

\begin{tabular}{|c|c|c|c|c|c|}
\hline \multirow{2}{*}{$\begin{array}{l}\text { Lugar de resi- } \\
\text { dencia anterior, } \\
\text { sexo y grupos } \\
\text { de edades }\end{array}$} & \multirow[t]{2}{*}{ Total } & \multicolumn{4}{|c|}{$\begin{array}{l}\text { Tiempo de residencia en la entidad } \\
\text { federativa de empadronamiento }\end{array}$} \\
\hline & & $\begin{array}{l}\text { menos de } \\
5 \text { años }\end{array}$ & $\begin{array}{l}5 \text { a } 9 \\
\text { años }\end{array}$ & $\begin{array}{l}10 \text { o más } \\
\text { años }\end{array}$ & $\begin{array}{l}\text { no especi- } \\
\text { ficado }\end{array}$ \\
\hline $\begin{array}{l}\text { Países } \\
\text { extranjeros }\end{array}$ & 523559 & 245375 & 71331 & 131938 & 74915 \\
\hline $\begin{array}{l}\text { Hombres } \\
0-4 \\
5-9 \\
10-14 \\
15-19 \\
20-24 \\
25-29 \\
30-34 \\
35-39 \\
40-44 \\
45-49 \\
50-54 \\
55-59 \\
60-64 \\
65 \text { o más }\end{array}$ & $\begin{array}{r}326854 \\
9896 \\
13906 \\
11598 \\
24188 \\
45264 \\
40648 \\
34431 \\
30082 \\
25282 \\
21770 \\
18268 \\
15249 \\
10468 \\
25804\end{array}$ & 155548 & 41171 & 79665 & 50470 \\
\hline $\begin{array}{l}\text { Mujeres } \\
0-4 \\
5-9 \\
10-14 \\
15-19 \\
20-24 \\
25-29 \\
30-34 \\
35-39 \\
40-44 \\
45-49 \\
50-54 \\
55-59 \\
60-64 \\
65 \text { o más }\end{array}$ & $\begin{array}{r}196705 \\
9733 \\
13708 \\
11904 \\
18306 \\
25940 \\
23927 \\
19513 \\
14144 \\
10524 \\
8769 \\
9060 \\
7879 \\
6545 \\
16753\end{array}$ & 89827 & 30160 & 52273 & 24445 \\
\hline
\end{tabular}


CUADRO 4. (Conclusión).

\begin{tabular}{|c|c|c|c|c|c|}
\hline \multirow{2}{*}{$\begin{array}{l}\text { Lugar de resi- } \\
\text { dencia anterior, } \\
\text { sexo y grupos } \\
\text { de edades }\end{array}$} & \multirow{2}{*}{ Total } & \multicolumn{4}{|c|}{$\begin{array}{l}\text { Tiempo de residencia en la entidad } \\
\text { federativa de empadronamiento }\end{array}$} \\
\hline & & $\begin{array}{l}\text { menos de } \\
5 \text { años }\end{array}$ & $\begin{array}{l}5 \text { a } 9 \\
\text { años }\end{array}$ & $\begin{array}{l}10 \text { o más } \\
\text { años }\end{array}$ & $\begin{array}{l}\text { no especi- } \\
\text { ficado }\end{array}$ \\
\hline No especificado & 1164468 & 382359 & 217345 & 564764 & 0 \\
\hline Hombres & 569534 & 191733 & 106888 & 270913 & 0 \\
\hline $0-4$ & 38601 & & & & \\
\hline $5-9$ & 47123 & & & & \\
\hline $10-14$ & 50200 & & & & \\
\hline $15-19$ & 57061 & & & & \\
\hline $20-24$ & 65691 & & & & \\
\hline $25-29$ & 58970 & & & & \\
\hline $30-34$ & 49887 & & & & \\
\hline $35-39$ & 44126 & & & & \\
\hline $40-44$ & 36090 & & & & \\
\hline $45-49$ & 30119 & & & & \\
\hline $50-54$ & 24241 & & & & \\
\hline $55-59$ & 19855 & & & & \\
\hline $60-64$ & 14515 & & & & \\
\hline 65 o más & 33055 & & & & \\
\hline Mujeres & 594934 & 190626 & 110457 & 293851 & 0 \\
\hline $0-4$ & 38186 & & & & \\
\hline $5-9$ & 46281 & & & & \\
\hline $10-14$ & 51847 & & & & \\
\hline $15-19$ & 65989 & & & & \\
\hline $20-24$ & 71006 & & & & \\
\hline $25-29$ & 61047 & & & & \\
\hline $30-34$ & 49058 & & & & \\
\hline $35-39$ & 43916 & & & & \\
\hline $40-44$ & 35164 & & & & \\
\hline $45-49$ & 31031 & & & & \\
\hline $50-54$ & 25429 & & & & \\
\hline $55-59$ & 19964 & & & & \\
\hline $60-64$ & 15704 & & & & \\
\hline 65 o más & 40312 & & & & \\
\hline
\end{tabular}




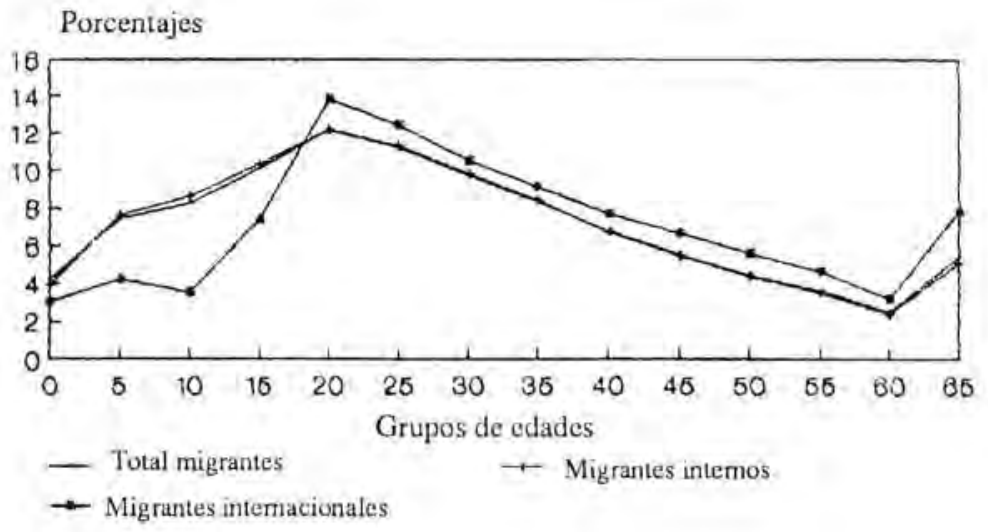

FIGURA 1.Migrantes: distribución relativa por edades. Hombres, 1980. FUENTE: Censo general de población y vivienda de 1980, Resumen general, Vol. II, cuadro 40.

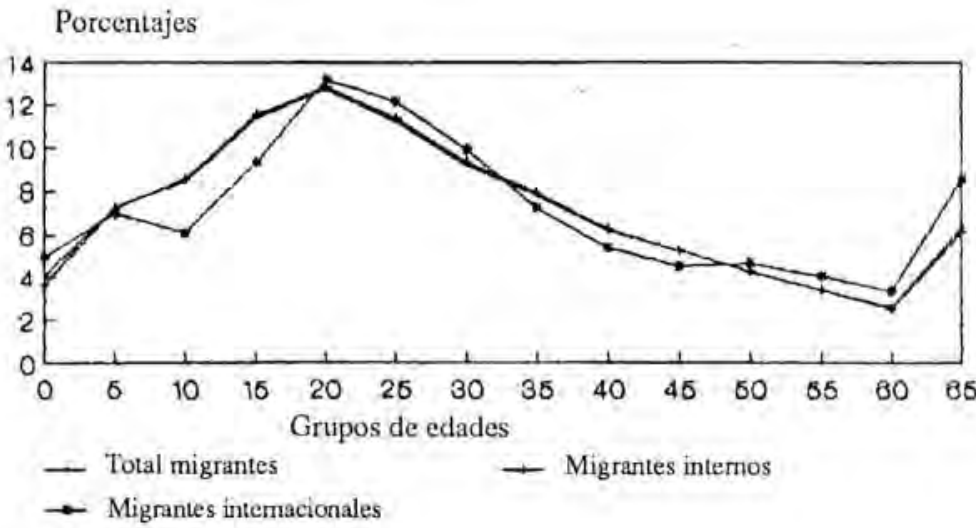

FIGURA 2,Migrantes: Distribución relativa por edades. Mujeres, 1980. FUENTE: Censo general de población y vivienda de 1980, Resumen general, Vol. II, cuadro 40. 
CUADRO 4.1. México: población que cambió de lugar de residencia, por tiempo de residencia en la entidad federativa de empadronamiento, según lugar de residencia anterior, sexo y grupos de edades (1980).

\begin{tabular}{|c|c|c|c|c|}
\hline \multirow{2}{*}{$\begin{array}{l}\text { Lugar de resi- } \\
\text { dencia anterior, } \\
\text { sexo y grupos } \\
\text { de edades }\end{array}$} & \multirow[t]{2}{*}{ Total } & \multicolumn{3}{|c|}{$\begin{array}{l}\text { Tiempo de residencia en la entidad } \\
\text { federativa de empadronamiento }\end{array}$} \\
\hline & & $\begin{array}{l}\text { menos de } \\
5 \text { años }\end{array}$ & $\begin{array}{l}5 \text { a } 9 \\
\text { años }\end{array}$ & $\begin{array}{l}10 \text { o más } \\
\text { años }\end{array}$ \\
\hline Total migrantes & 8979892 & 3360912 & 1829913 & 3789067 \\
\hline Hombres & 4447854 & 1708964 & 906822 & 1832068 \\
\hline $0-4$ & 188081 & 188081 & & \\
\hline $5-9$ & 332834 & 210887 & 121947 & \\
\hline $10-14$ & 368810 & 152944 & 127217 & 88649 \\
\hline $15-19$ & 450102 & 199373 & 98083 & 152646 \\
\hline $20-24$ & 543395 & 266738 & 109121 & 167536 \\
\hline $25-29$ & 501773 & 217790 & 113527 & 170456 \\
\hline $30-34$ & 433489 & 154107 & 95966 & 183416 \\
\hline $35-39$ & 373865 & 104826 & 77173 & 191866 \\
\hline $40-44$ & 300848 & 67618 & 52763 & 180467 \\
\hline $45-49$ & 245844 & 46747 & 36472 & 162625 \\
\hline $50-54$ & 197415 & 32007 & 25129 & 140279 \\
\hline $55-59$ & 159779 & 22787 & 17693 & 119299 \\
\hline $60-64$ & 110767 & 15216 & 11116 & 84435 \\
\hline 65 o más & 240852 & 29843 & 20615 & 190394 \\
\hline Mujeres & 4532038 & 1651948 & 923091 & 1956999 \\
\hline $0-4$ & 185162 & 185162 & & \\
\hline $5-9$ & 329195 & 208885 & 120310 & \\
\hline $10-14$ & 383015 & 169087 & 126518 & 87410 \\
\hline $15-19$ & 516692 & 257118 & 108193 & 151381 \\
\hline $20-24$ & 576839 & 268282 & 135052 & 173505 \\
\hline $25-29$ & 509307 & 187953 & 126694 & 194660 \\
\hline $30-34$ & 416160 & 116621 & 93277 & 206262 \\
\hline $35-39$ & 353926 & 75095 & 67134 & 211697 \\
\hline $40-44$ & 278449 & 46757 & 43218 & 188474 \\
\hline $45-49$ & 235170 & 33847 & 30321 & 171002 \\
\hline $50-54$ & 193202 & 26336 & 21285 & 145581 \\
\hline $55-59$ & 153848 & 20666 & 15561 & 117621 \\
\hline $60-64$ & 116494 & 16245 & 11224 & 89025 \\
\hline 65 o más & 284579 & 39894 & 24304 & 220381 \\
\hline
\end{tabular}


CUADRO 4.1. (Continuación),

\begin{tabular}{|c|c|c|c|c|}
\hline \multirow{2}{*}{$\begin{array}{l}\text { Lugar de resi- } \\
\text { dencia anterior, } \\
\text { sexo y grupos } \\
\text { de edades }\end{array}$} & \multirow[t]{2}{*}{ Total } & \multicolumn{3}{|c|}{$\begin{array}{l}\text { Tiempo de residencia en la entidad } \\
\text { federativa de empadronamiento }\end{array}$} \\
\hline & & $\begin{array}{l}\text { menos de } \\
5 \text { años }\end{array}$ & $\begin{array}{l}5 \text { a } 9 \\
\text { años }\end{array}$ & $\begin{array}{l}10 \text { o más } \\
\text { años }\end{array}$ \\
\hline Entidades & & & & \\
\hline federativas & 8379100 & 3033227 & 1735175 & 3610698 \\
\hline Hombres & 4073781 & 1499008 & 851394 & 1723379 \\
\hline $0-4$ & 175630 & 175630 & & \\
\hline $5-9$ & 316634 & 197963 & 118671 & \\
\hline $10-14$ & 355385 & 144166 & 124023 & 87196 \\
\hline $15-19$ & 422402 & 180297 & 93875 & 148230 \\
\hline $20-24$ & 491907 & 229569 & 102122 & 160216 \\
\hline $25-29$ & 455712 & 186772 & 106105 & 162835 \\
\hline $30-34$ & 394580 & 130737 & 89232 & 174611 \\
\hline $35-39$ & 339757 & 87178 & 71083 & 181496 \\
\hline $40-44$ & 272120 & 54817 & 48025 & 169278 \\
\hline $45-49$ & 221035 & 36921 & 32810 & 151304 \\
\hline $50-54$ & 176590 & 24705 & 22354 & 129531 \\
\hline $55-59$ & 142366 & 17270 & 15596 & 109500 \\
\hline $60-64$ & 98720 & 11497 & 9790 & 77433 \\
\hline 65 o más & 210943 & 21486 & 17708 & 171749 \\
\hline Mujeres & 4305319 & 1534219 & 883781 & 1887319 \\
\hline $0-4$ & 172900 & 172900 & & \\
\hline $5-9$ & 313245 & 196878 & 116367 & \\
\hline $10-14$ & 369247 & 160601 & 122890 & 85756 \\
\hline $15-19$ & 495706 & 242771 & 104751 & 148184 \\
\hline $20-24$ & 547258 & 249062 & 129470 & 168726 \\
\hline $25-29$ & 482121 & 172749 & 120802 & 188570 \\
\hline $30-34$ & 394039 & 106328 & 88504 & 199207 \\
\hline $35-39$ & 337778 & 68912 & 63943 & 204923 \\
\hline $40-44$ & 266404 & 42851 & 41139 & 182414 \\
\hline $45-49$ & 225068 & 30926 & 28808 & 165334 \\
\hline $50-54$ & 182769 & 23464 & 19940 & 139365 \\
\hline $55-59$ & 144794 & 18203 & 14471 & 112.120 \\
\hline $60-64$ & 108929 & 14123 & 10359 & 84447 \\
\hline 65 o más & 265061 & 34451 & 22337 & 208273 \\
\hline
\end{tabular}


CUADRO 4.1. (Conclusión).

\begin{tabular}{|c|c|c|c|c|}
\hline \multirow{2}{*}{$\begin{array}{l}\text { Lugar de resi- } \\
\text { dencia anterior, } \\
\text { sexo y grupos } \\
\text { de edades }\end{array}$} & \multirow[t]{2}{*}{ Total } & \multicolumn{3}{|c|}{$\begin{array}{l}\text { Tiempo de residencia en la entidad } \\
\text { federativa de empadronamiento }\end{array}$} \\
\hline & & $\begin{array}{l}\text { menos de } \\
5 \text { años }\end{array}$ & $\begin{array}{l}5 \text { a } 9 \\
\text { años }\end{array}$ & $\begin{array}{l}10 \text { o más } \\
\text { años }\end{array}$ \\
\hline $\begin{array}{l}\text { Países } \\
\text { extranjeros }\end{array}$ & 600792 & 327685 & 94738 & 178369 \\
\hline Hombres & 374073 & 209956 & 55428 & 108689 \\
\hline $0-4$ & 12451 & 12451 & & \\
\hline $5-9$ & 16200 & 12924 & 3276 & \\
\hline $10-14$ & 13425 & 8778 & 3194 & 1453 \\
\hline $15-19$ & 27700 & 19076 & 4208 & 4416 \\
\hline $20-24$ & 51488 & 37169 & 6999 & 7320 \\
\hline $25-29$ & 46061 & 31018 & 7422 & 7621 \\
\hline $30-34$ & 38909 & 23370 & 6734 & 8805 \\
\hline $35-39$ & 34108 & 17648 & 6090 & 10370 \\
\hline $40-44$ & 28728 & 12801 & 4738 & 11189 \\
\hline $45-49$ & 24809 & 9826 & 3662 & 11321 \\
\hline $50-54$ & 20825 & 7302 & 2775 & 10748 \\
\hline $55-59$ & 17413 & 5517 & 2097 & 9799 \\
\hline $60-64$ & 12047 & 3719 & 1326 & 7002 \\
\hline 65 o más & 29909 & 8357 & 2907 & 18645 \\
\hline Mujeres & 226719 & 117729 & 39310 & 69680 \\
\hline $0-4$ & 12262 & 12262 & & \\
\hline $5-9$ & 15950 & 12007 & 3943 & \\
\hline $10-14$ & 13768 & 8486 & 3628 & 1654 \\
\hline $15-19$ & 20986 & 14347 & 3442 & 3197 \\
\hline $20-24$ & 29581 & 19220 & 5582 & 4779 \\
\hline $25-29$ & 27186 & 15204 & 5892 & 6090 \\
\hline $30-34$ & 22121 & 10293 & 4773 & 7055 \\
\hline $35-39$ & 16148 & 6183 & 3191 & 6774 \\
\hline $40-44$ & 12045 & 3906 & 2079 & 6060 \\
\hline $45-49$ & 10102 & 2921 & 1513 & 5668 \\
\hline $50-54$ & 10433 & 2872 & 1345 & 6216 \\
\hline $55-59$ & 9054 & 2463 & 1090 & 5501 \\
\hline $60-64$ & 7565 & 2122 & 865 & 4578 \\
\hline 65 o más & 19518 & 5443 & 1967 & 12108 \\
\hline
\end{tabular}

FUENTE: Cuadro 4 y cálculos propios. 
Las cantidades finales resultantes de la distribución se presentan en el cuadro 4.1.

$\mathrm{El}$ aspecto que fue preciso considerar posteriormente en el procedimiento de estimación de la inmigración internacional fue el relativo a un grupo nada despreciable de personas (2'443,536 hombres y 2'625,039 mujeres; ver cuadro 5), cuyas respuestas a dos preguntas incluidas en el cuestionario del censo de 1980 ponen en evidencia un grave problema de inconsistencia. En la revisión bibliográfica de los trabajos sobre el tema fue posible tomar conocimiento (Partida, 1990) de la existencia de una tabulación inédita, conformada por poco más de 5 millones de personas ( $7.6 \%$ del total de población residente en Mẻxico), clasificadas por sexo y grupos de edades, que a la pregunta: ¿nació en este estado o entidad federativa?, contestaron "no", y a la pregunta ¿ha vivido más de seis meses fuera de este estado o entidad federativa?, también contestaron "no". La respuesta negativa a ambas preguntas constituye claramente una gran incongruencia, puesto que no es posible que una persona que no nació en el lugar donde reside actualmente no haya residido previamente más de seis meses en otro lugar. ${ }^{11}$ El problema en cuestión, entonces, se deriva de las respuestas contradictorias a aquellas dos preguntas censales, lo que genera una categoría muy particular de "no especificados" — que denominaremos "no nació allí ni residió fuera"-, dentro de la cual se ubica un importante número de individuos cuya condición migratoria es incierta.

La primera de las dos preguntas en cuestión es muy sencilla, está presente en casi todos los censos de población del mundo y de ella se obtienen, en general, muy buenos resultados; por otra parte, la contestación correcta a esta interrogante no depende fundamentalmente (como sí ocurre con otras preguntas censales) de la forma en que es realizada por el entrevistador, pudiéndose también obtener la respuesta adecuada a partir de preguntas similares. La segunda en cambio, es una pregunta nueva en la historia de los censos de población mexicanos, cuyos resultados dependen esencialmente de la forma en que es formulada. ${ }^{12}$ A partir de estas situaciones se optó por considerar como correcta la

\footnotetext{
11 Existen dos casos extrumos en los cuales sí se podría dar esta situación: el primero, por demás improbable, es el de aquella persona que haya estado migrando de un sitio a otro toda su vida hasta el presente, sin permanecer nunca más de seis meses en determinado lugar; el segundo, cuya frecuencia absoluta debe ser seguramente muy poco significativa, es el de las personas que han emigrado de su lugar de nacimiento (a su lugar de residencia actual) antes de cumplir los séis meses de vida.

${ }^{12}$ En el censo de población de México de 1980 hay más de 5.8 millones de personas de quienes no se obtuvo respuesta a esa pregunta (ver cuadro 37 del volumen in del Resumen general).
} 
CUADRO 5. México: número de personas que declararon en el censo de población de 1980 "no haber nacido en la entidad de empadronamiento, ni haber residido más de seis meses fuera de ella", por sexo, según grupos de edades.

\begin{tabular}{lrrr}
\hline Grupos de edades & \multicolumn{1}{c}{ Total } & Hombres & \multicolumn{1}{c}{ Mujeres } \\
\hline Total & 5068575 & 2443536 & 2625039 \\
$0-4$ & 367345 & 185087 & 182258 \\
$5-9$ & 451075 & 226913 & 224162 \\
$10-14$ & 461703 & 230151 & 231552 \\
$15-19$ & 485287 & 232092 & 253195 \\
$20-24$ & 512554 & 238753 & 273801 \\
$25-29$ & 479568 & 225748 & 253820 \\
$30-34$ & 430596 & 208018 & 222578 \\
$35-39$ & 395816 & 191555 & 204261 \\
$40-44$ & 331809 & 162444 & 169365 \\
$45-49$ & 284736 & 136651 & 148085 \\
$50-54$ & 233852 & 111250 & 122602 \\
$55-59$ & 188088 & 91802 & 96286 \\
$60-64$ & 135695 & 63853 & 71842 \\
65 o más & 310451 & 139219 & 171232 \\
\hline
\end{tabular}

FUENTE: Partida, Virgilio, "Estimación de la Migración Internacional Mexicana, 1960-1980", 1990.

respuesta a la pregunta sobre lugar de nacimiento $y$, por lo tanto, incorrecta la correspondiente a la otra pregunta; en otras palabras, se asumió que todas las personas incluidas en la categoría "no nació allí ni residió fucra" son también migrantes de acuerdo a las preguntas sobre residencia previa.

Aceptado lo anterior, se procedió a distribuir este conjunto de personas (clasificados por sexo y grupos de edades) por tiempo de residencia en el lugar de empadronamiento y lugar de residencia anterior. A falta de elementos de juicio que permitieran trabajar en forma más refinada se optó por realizar la distribución en forma proporcional a las cifras estimadas hasta el momento. ${ }^{13}$ 
Otro punto que no es posible pasar por alto al intentar obtener estimaciones de la inmigración internacional es el relacionado con el conjunto de personas de las cuales se desconoce su condición migratoria. De acuerdo al cuadro 37 del volumen II del Resumen general del censo de población de 1980 , existirian 5'878,409 personas (8.8\% del total de población empadronada) de quienes no se tiene información sobre su condición migratoria. Este conjunto de personas está conformado por 2'885,334 hombres y 2'993,075 mujeres que no respondieron a la pregunta que define la condición migratoria de un individuo (migrante o no migrante) en función de su lugar de residencia anterior: $\iota$ ha vivido más de seis meses fuera de este estado o entidad federativa?

Desde un punto de vista teórico, y en forma previa a cualquier tipo de análisis, sería lógico pensar que este grupo de personas de condición migratoria no especificada se divide en: migrantes (internos e internacionales) y no migrantes. Por esta razón, y dada la importancia numérica de la población perteneciente a esa categoría, pensamos que cualquier intento de estimación de la migración internacional a partir de datos censales no puede dejar de tomar en cuenta a aquella población dentro del tratamiento de la información básica.

En este sentido, se procedió a realizar un análisis comparando las cifras de migrantes de acuerdo a la pregunta sobre lugar de nacimiento (migrantes absolutos) con las derivadas de la pregunta sobre residencia previa. Este examen, cuyos resultados obviamente están condicionados por la información disponible, nos llevó a la conclusión de que los individuos dentro de la categoria "condición migratoria no especificada" son todos no migrantes, y por ello, ninguna parte de este conjunto fue adicionada a la población total que cambió de lugar de residencia, hasta ahora estimada.

La siguiente instancia del procedimiento de estimación fue la apertura del grupo de edades abierto "65 o más", de cada sexo de la población inmigrante internacional clasificada por tiempo de residencia, en grupos quinquenales de edades hasta el abierto final "85 o más" (cuadro 6). La distribución de dicho grupo de edades se realizó por extrapolación, empleando la técnica de la "Ojiva de ejes oblicuos" (Carrier y Farrag, 1961).

\footnotetext{
${ }^{13}$ No es posible dejar de advertir que esta forma de distribución podría no apegarse estrictamente a la realidad. No sería demasiado improbable, por ejemplo, - dado el tipo de contradicción derivado de las respuestas obtenidas-que dentro de la población perteneciente a la categoría "no nació allí ni residio fuera" existiera un importante número de personas que hace mucho tiempo que residen en la entidad federativa donde fueron empadronados. A pesar de ello, creemos que dadas las limitaciones de la información disponible, ésta es la alternativa de distribución más aceptable, puesto que cualquier otra sería bastante arbitraria y seguramente contendría un mayor margen de error.
} 
CUADRO 6. México: población total de inmig, internacionales,* por tiempo de residencia en la entidad federativa de empadronamiento, según sexo y grupos de edades (1980).

\begin{tabular}{|c|c|c|c|c|}
\hline \multirow[t]{2}{*}{$\begin{array}{l}\text { Sexo y grupos } \\
\text { de edades }\end{array}$} & \multirow[t]{2}{*}{ Total } & \multicolumn{3}{|c|}{$\begin{array}{l}\text { Tiempo de residencia en la entidad } \\
\text { federativa de empadronamiento }\end{array}$} \\
\hline & & Menos de 5 an̆os & 5 a 9 años & 10 o más años \\
\hline Total inmig. intern. & 934180 & 511582 & 145723 & 276875 \\
\hline Hombres & 574800 & 323510 & 84397 & 166893 \\
\hline $0-4$ & 24704 & 24704 & & \\
\hline $5-9$ & 27245 & 21735 & 5510 & \\
\hline $10-14$ & 21803 & 14256 & 5187 & 2360 \\
\hline $15-19$ & 42881 & 29810 & 6378 & 6693 \\
\hline $20-24$ & 75773 & 55163 & 10074 & 10536 \\
\hline $25-29$ & 69888 & 46370 & 11011 & 12507 \\
\hline $30-34$ & 60604 & 35659 & 10196 & 14749 \\
\hline $35-39$ & 54694 & 27519 & 9423 & 17752 \\
\hline $40-44$ & 46793 & 20325 & 7465 & 19003 \\
\hline $45-49$ & 41397 & 15763 & 5698 & 19936 \\
\hline $50-54$ & 34777 & 11417 & 4339 & 19021 \\
\hline $55-59$ & 29453 & 8687 & 3302 & 17464 \\
\hline $60-64$ & 20448 & 5863 & 2090 & 12495 \\
\hline $65-69$ & 11263 & 3024 & 1383 & 6856 \\
\hline $70-74$ & 6770 & 2035 & 1092 & 3643 \\
\hline $75-79$ & 3484 & 764 & 791 & 1929 \\
\hline $80-84$ & 2087 & 324 & 333 & 1430 \\
\hline 85 o más & 736 & 92 & 125 & 519 \\
\hline Mujeres & 359380 & 188072 & 61326 & 109982 \\
\hline $0-4$ & 24332 & 24332 & & \\
\hline $5-9$ & 26811 & 20183 & 6628 & \\
\hline $10-14$ & 22091 & 13616 & 5821 & 2654 \\
\hline $15-19$ & 31788 & 21896 & 5129 & 4763 \\
\hline $20-24$ & 44309 & 29030 & 8232 & 7047 \\
\hline $25-29$ & 41840 & 23333 & 8795 & 9712 \\
\hline $30-34$ & 35031 & 16181 & 7326 & 11524 \\
\hline $35-39$ & 26153 & 9751 & 5033 & 11369 \\
\hline $40-44$ & 20848 & 6282 & 3343 & 11223 \\
\hline $45-49$ & 18620 & 5260 & 2466 & 10894 \\
\hline $50-54$ & 16142 & 4195 & 2199 & 9748 \\
\hline $55-59$ & 14720 & 4004 & 1772 & 8944 \\
\hline $60-64$ & 12230 & 3431 & 1398 & 7401 \\
\hline $65-69$ & 9846 & 2594 & 1146 & 6106 \\
\hline $70-74$ & 7064 & 2049 & 945 & 4070 \\
\hline $75-79$ & 4134 & 1098 & 674 & 2362 \\
\hline $80-84$ & 2443 & 594 & 232 & 1617 \\
\hline 85 o más & 978 & 243 & 187 & 548 \\
\hline
\end{tabular}

FUENTE: Censo general de población y vivienda de 1980 y cálculos propios.

*Personas cuyo lugar de residencia anterior al actual fue un pás extranjero. 
A continuación se procedió a trabajar con la información referida a la población nacida en el exterior. Gracias a una tabulación inédita ${ }^{14}$ fue posible contar con una distribución por grupos de edades de la población extranjera residente en México en 1980. En el cuadro 7 se presenta esta población clasificada por sexo, según grupos quinquenales y decenales de edades. Al observar el tabulado, inmediatamente llama la atención el alto número (en términos absolutos y relativos) de personas pertenecientes a los grupos de edades $0-4$ y 5-9. De hecho, la relación niños-mujeres ${ }^{15}$ que se deduce de la distribuciôn por edad y sexo ( $R N M=0,726)$, se ubica en niveles similares a los observados en las zonas rurales de algunos países latinoamericanos.

Lo anterior, que obviamente está evidenciando algún tipo de problemas en la enumeración de los primeros grupos de edades, ${ }^{16}$ nos llevó a pensar en algún momento en la posibilidad de descartar dicha información. Finalmente, ante la falta de otro tipo de datos que nos permitiera corregir la sobreenumeración de aquellos grupos de edades, se decidió continuar trabajando con ella, en el entendido de que el error en cuestión seguramente no afectaría en forma demasiado significativa a las estimaciones finales.

Acto seguido, se pasó a obtener la distribución de la población extranjera de cada sexo, según grupos quinquenales de edades, hasta el abierto final " 850 más"; paraello se recurrió nuevamente a la técnica de la "Ojiva de ejes oblicuos", previa distribución en forma proporcional del rubro "no especificado".

EI siguiente paso correspondió a la obtención de la clasificación de la población extranjera, por tiempo de residencia en la entidad de empadronamiento, según sexo y grupos de edades. En la etapa precedente se había obtenido la población total nacida en el exterior clasificada según sexo y grupos quinquenales de edades; por otro lado, el cuadro 38 del volumen II del Resumen general del censo de 1980, nos proporcionaba la clasificación de la población extranjera por tiempo de residencia según sexo. ${ }^{17}$ Lo único que faltaba era, entonces, estimar la distribución por grupos de edades de los totales de población de cada sexo

\footnotetext{
${ }^{14}$ Proporcionada amablemente por el señor Virgilio Partida, investigador de El Colegio de México.

15 La relación niños-mujeres (RNM) se calcula generalmente como el cociente entre la población menor de 5 años y los efectivos femeninos del grupo de edades 15-49.

16 Una explicación a este problema de sobreenumeración podría ser la existencia de un número indeterminado de madres mexicanas residentes cerca de la frontera con Éstados Unidos, que han ido a dar a luz al vecino país del norte, y que, posteriormente, en el censo de población mexicano, declararon a sus hijos como nacidos en aquel país.

La categoría "no especificado" se distribuyó en forma proporcional.
} 
pertenecientes a cada una de las tres categorías de tiempo de residencia. Esta estimación se llevó a cabo por medio del procedimiento de la "tabla cuadrada". La técnica se aplicó por sexo, siendo los marginales horizontales las cifras de la distribución según grupos de edades, y los marginales verticales, las cantidades derivadas de la clasificación por tiempo de residencia; el arreglo inicial surgió de distribuir los montos de población de cada grupo de edades por tiempo de residencia, en forma proporcional a partir de la distribución del cuadro 6; las estimaciones finales se presentan en el cuadro 8 .

CUADRO 7. México: población nacida en el exterior, por sexo según grupos de edades (1980).

\begin{tabular}{lrrr}
\hline Grupos de edades & Total & Hombres & Mujeres \\
\hline Total & 272294 & 135897 & 136397 \\
$0-4$ & 38378 & 19269 & 19109 \\
$5-9$ & 38668 & 19292 & 19376 \\
$10-14$ & 21563 & 10601 & 10962 \\
$15-19$ & 14902 & 7184 & 7718 \\
$20-24$ & 15343 & 7440 & 7903 \\
$25-34$ & 32410 & 15258 & 17152 \\
$35-44$ & 24821 & 12670 & 12151 \\
$45-54$ & 30488 & 15553 & 14935 \\
$55-64$ & 25734 & 12709 & 13025 \\
65 o más & 26552 & 14215 & 12337 \\
No especificado & 3435 & 1706 & 1729 \\
\hline
\end{tabular}

FUENTE: Tabulación inédita del $x$ Censo General de Población, 1980; proporcionada por Virgilio Partida.

NOTA: A las cifras originales contenidas en el rubro "no especificado" (21 hombres y 20 mujeres) le fueron adicionadas 1,685 hombres y 1,709 mujeres, correspondientes a la distribución proporcional de la categoría "no especificado" del cuadro 36 del volumen II del Resumen general del censo de población y vivienda de 1980. 
CUADRO 8. México: estimación del número de personas nacidas en el exterior por tiempo de residencia en la entidad federativa de empadronamiento, según sexo y grupos de edades(1980).

\begin{tabular}{|c|c|c|c|c|}
\hline \multirow[t]{2}{*}{$\begin{array}{l}\text { Sexo y grupos } \\
\text { de edades }\end{array}$} & \multirow[t]{2}{*}{ Total } & \multicolumn{3}{|c|}{$\begin{array}{l}\text { Tiempo de residencia en la entidad } \\
\text { federativa de empadronamiento }\end{array}$} \\
\hline & & menos de 5 años & 5 a 9 años & 10 o más años \\
\hline $\begin{array}{l}\text { Población nacida en } \\
\text { el extranjero }\end{array}$ & 272294 & 121690 & 43406 & 107198 \\
\hline Hombres & 135897 & 61949 & 21617 & 52331 \\
\hline $0-4$ & 19514 & 19514 & & \\
\hline $5-9$ & 19536 & 14541 & 4995 & \\
\hline $10-14$ & 10736 & 5022 & 3531 & 2183 \\
\hline $15-19$ & 7275 & 3588 & 1360 & 2327 \\
\hline $20-24$ & 7535 & 3920 & 1399 & 2216 \\
\hline $25-29$ & 7813 & 3454 & 1593 & 2766 \\
\hline $30-34$ & 7639 & 2608 & 1506 & 3525 \\
\hline $35-39$ & 7447 & 2046 & 1403 & 3998 \\
\hline $40-44$ & 7254 & 1543 & 1167 & 4544 \\
\hline $45-49$ & 7073 & 1304 & 889 & 4880 \\
\hline $50-54$ & 6853 & 1025 & 745 & 5083 \\
\hline 55.59 & 6563 & 879 & 591 & 5093 \\
\hline $60-64$ & 6263 & 771 & 543 & 4949 \\
\hline $65-69$ & 5613 & 672 & 544 & 4397 \\
\hline $70-74$ & 4413 & 689 & 655 & 3069 \\
\hline $75-79$ & 2813 & 278 & 511 & 2024 \\
\hline $80-84$ & 1114 & 72 & 131 & 911 \\
\hline 85 o más & 443 & 23 & 54 & 366 \\
\hline Mujeres & 136397 & 59741 & 21789 & 54867 \\
\hline $0-4$ & 19355 & 19355 & & \\
\hline $5-9$ & 19625 & 13423 & 6202 & \\
\hline $10-14$ & 11103 & 5403 & 3383 & 2317 \\
\hline $15-19$ & 7817 & 4132 & 1428 & 2257 \\
\hline $20-24$ & 8004 & 3947 & 1650 & 2407 \\
\hline $25-29$ & 7950 & 2940 & 1664 & 3346 \\
\hline $30-34$ & 7770 & 2247 & 1502 & 4021 \\
\hline $35-39$ & 7529 & 1605 & 1222 & 4702 \\
\hline $40-44$ & 7290 & 1162 & 912 & 5216 \\
\hline $45-49$ & 7210 & 1045 & 724 & 5441 \\
\hline $50-54$ & 7057 & 927 & 716 & 5414 \\
\hline $55-59$ & 6792 & 933 & 612 & 5247 \\
\hline $60-64$ & 6400 & 911 & 549 & 4940 \\
\hline $65-69$ & 5250 & 694 & 452 & 4104 \\
\hline $70-74$ & 3750 & 562 & 383 & 2805 \\
\hline $75-79$ & 2049 & 280 & 254 & 1515 \\
\hline $80-84$ & 950 & 112 & 64 & 774 \\
\hline 85 o más & 496 & 63 & 72 & 361 \\
\hline
\end{tabular}

FUENTE: Cálculos propios con base en información del Censo general de población y vivienda de 1980. 
La etapa siguiente del procedimiento tuvo como objetivo estimar el númcro de inmigrantes internacionales e inmigrantes extranjeros, clasificados por sexo y grupos de edades, sobrevivientes al final de cada uno de los tres períodos de migración que se han considerado hasta el momento: 19751980, 1970-1975 y antes de 1970. Las estimaciones se obtuvieron retroproyectando las cifras de población presentadas en los cuadros 6 y 8 respeclivamente, con las relaciones de sobrevivencia representativas de la mortalidad promedio en cada período quinquenal (ver cuadro 9). ${ }^{18}$

Posteriormente, a partir de las estimaciones por sexo y edad de inmigrantes internacionales e inmigrantes extranjeros sobrevivientes en 1970, se pasó a obtener la distribución por período de llegada de esos migrantes, considerando los intervalos de migración 1965-1970, 1960-1965 y antes de 1960. Esta distribución se logró procediendo de la siguiente manera: primero, se calculó la distribución relativa de los datos contenidos en el censo de población de 1970, referidos a la clasificación por tiempo de residencia ${ }^{19}$ y sexo de los inmigrantes internacionales enumerados en esa ocasión (personas cuya última residencia anterior fue un país extranjero); aplicando luego esta distribución al número ya estimado de inmigrantes sobrevivientes en 1970 (el total de inmigrantes y los extranjeros ) se estimó el número total de inmigrantes internacionales e inmigrantes extranjeros de cada sexo, llegados en cada uno de los tres períodos de migración; luego, los montos estimados de población en cada sexo y grupo de edades del total de inmigrantes internacionales y de los inmigrantes extranjeros, sobrevivientes en 1970, fueron distribuidos por período de llegada en

\footnotetext{
18 La desagregación de los grupos de edades abiertos "80 o más" y "75 o más" de los períodos de migración 1970-1975 y antes de 1970 respectivamente, se reslizó de la siguiente forma: en el primer caso se utilizó la estructura intema del grupo de edades " 80 o más" de la población migrante del período $1975-1980$ del sexo correspondiente sobreviviente en 1980 (considerando el total de inmigrantes internacionales o los inmigrantes extranjcros segün correspondiera); por su parte, la apentura del grupo de edades "75 o más" en cada sexo de los migrantes del período anterior a 1970 , se obtuvo apliçando a dicho grupó la estructura intema de ese intervalo de edades según la distribución por sexo y edades de la población total inmigrante intemacional o el total de efectivos nacidos en el extranjero, según fuera el caso, sobrevivientes en 1980.

19 Fue preciso modificar las categorias de la clasificación por tiempo de residencis usadas en el cunso de 1970 para haeerlos comparables con los intervalos utilizados en 1980 . En este sentido, la clasificación por tiempo de residencia en el lugar de empadronamiento fue transformada a los nuevos intervalos - "menos de 1 año", " 1 a 4 años"," "5 a 9 años" y "10 o más años"- de la siguiente manera (previa distribución proporcional del rubro "no especificudo"): menos de 1 año: pernaneció igual a como estaba; 1 a 4 años: se fonnó cóno Ia suma del grupo "1 a 2 años" más dos tercios del grupo "3 a 5 años", 5 a 9 años: se fomló como la suma de un têrciu del grupo " 3 a 5 años" más cuatro quintos del grupo "6 a 10 años"; 10 o más años; se formó como la suma de un quinto del grupo "6 a 10 años" más el grupo "11 o más años".
} 
forma análoga a la distribución de los migrantes sobrevivientes en 1980 de los cuadros 6 y 8 respectivamente; finalmente, utilizando la técnica iterativa de climinación de la diferencia por aproximaciones sucesivas, se hizo cuadrar las cifras de la distribución anterior (arreglo inicial) con los totales de población por período de migración (marginales verticales), y la distribución según sexo y grupos de edades de los migrantes sobrevivientes en 1970 ya estimados (marginales horizontales). Recurriéndose nuevamente a las relaciones de sobrevivencia del cuadro 9 , se concluyó la estimación del número de inmigrantes internacionales e inmigrantes extranjeros llegados al país antes de 1970, clasificados por sexo y grupos de edades, sobrevivientes al final de cada período de llegada. ${ }^{20}$

En los cuadros 10 y 11 se presentan las estimaciones respectivas de inmigrantes internacionales e inmigrantes extranjeros sobrevivientes al final de cada período quinquenal de llegada de interés, clasificados según sexo y grupos de edades.

En esta parte es pertinente puntualizar:

a) En el procedimiento de estimación de la migración internacional se trabajó con el supuesto de que la mortalidad de nacionales y extranjeros es la misma, sin diferencia de que residan en México o en otro país.

b) El hecho de que en relación con la población extranjera se haga una analogía entre la clasificación censal por tiempo de residencia en la entidad de empadronamiento y el intervalo de migración en el cual se produjo su Ilegada al país, pone en evidencia el siguiente supuesto de trabajo: no existe migración interna de extranjeros, o ésta es despreciable. De una muestra del $10 \%$ del censo de 1970 se obtuvo que el $99.6 \%$ de la población extranjera masculina y el $99.4 \%$ de la femenina procedían directamente del exterior (Partida, 1990); aceptando que estas proporciones no tendrían por qué haber descendido significativamente para 1980, el supuesto adoptado queda sólidamente respaldado.

A continuación se procedió a estimar el número de migrantes de retorno sobrevivientes al final de cada período quinquenal de migración que habían emigrado previamente en el mismo lustro en que se produjo su regreso al país y que deberán, por consiguiente, ser tomados en cuenta también en las estimaciones de emigrantes de cada quinquenio. Con este fin, se recurrió al empleo de una tabla de estancia en Estados Unidos para trabajadores mexicanos indocumentados que regresaron por cuenta propia (Cervera, 1979), El primer paso que se dio fue estimar el

${ }^{20}$ La desagregación de los grupos de edades abiertos "80 o más" y "75 o más", de los períodos de migración 1960-1965 y antes de 1960 respectivamente se realizó en forma análoga a la indicada en la nota 18. 
CUADRO 9. México: relaciones de sobrevivencia por intervalos quinquenales, según sexo y grupos de edades, periodo 1960-1980.

\begin{tabular}{ccccc}
\hline $\begin{array}{c}\text { Sexo y grupos } \\
\text { de edades }\end{array}$ & $1960-1965$ & $1965-1970$ & $1970-1975$ & $1975-1980$ \\
\hline Hombres & & & & \\
$5 \mathrm{~Pb}$ & 0.889918 & 0.899309 & 0.914458 & 0.929362 \\
$0-4$ & 0.968141 & 0.972332 & 0.977910 & 0.984874 \\
$5-9$ & 0.991029 & 0.991989 & 0.993160 & 0.994543 \\
$10-14$ & 0.990937 & 0.991696 & 0.992389 & 0.993015 \\
$15-19$ & 0.984257 & 0.985398 & 0.985998 & 0.986057 \\
$20-24$ & 0.978272 & 0.979795 & 0.980418 & 0.980141 \\
$25-29$ & 0.975087 & 0.976816 & 0.977545 & 0.977274 \\
$30-34$ & 0.971403 & 0.973394 & 0.974579 & 0.974959 \\
$35-39$ & 0.965813 & 0.968057 & 0.969677 & 0.970673 \\
$40-44$ & 0.957258 & 0.959782 & 0.961748 & 0.963156 \\
$45-49$ & 0.945035 & 0.947894 & 0.950381 & 0.952497 \\
$50-54$ & 0.925860 & 0.929132 & 0.932750 & 0.936715 \\
$55-59$ & 0.898431 & 0.902379 & 0.907040 & 0.912414 \\
$60-64$ & 0.856194 & 0.861159 & 0.866869 & 0.873324 \\
$65-69$ & 0.796123 & 0.802295 & 0.811174 & 0.822762 \\
$70-74$ & 0.725188 & 0.733118 & 0.744965 & 0.760729 \\
$75-79$ & 0.643776 & 0.654710 & 0.668631 & 0.685541 \\
80 o más & 0.397271 & 0.403313 & 0.410871 & 0.419945 \\
Mujeres & & & & \\
$5 P b$ & 0.907300 & 0.914491 & 0.925406 & 0.940045 \\
$0-4$ & 0.968585 & 0.972189 & 0.977784 & 0.985371 \\
$5-9$ & 0.990917 & 0.992282 & 0.993894 & 0.995751 \\
$10-14$ & 0.992636 & 0.993764 & 0.994878 & 0.995977 \\
$15-19$ & 0.988701 & 0.990505 & 0.992217 & 0.993837 \\
$20-24$ & 0.985076 & 0.987125 & 0.989304 & 0.991614 \\
$25-29$ & 0.982024 & 0.984237 & 0.986695 & 0.989398 \\
$30-34$ & 0.978062 & 0.980408 & 0.983141 & 0.986261 \\
$35-39$ & 0.973882 & 0.976172 & 0.979041 & 0.982488 \\
$40-44$ & 0.968595 & 0.970856 & 0.973909 & 0.977753 \\
$45-49$ & 0.959856 & 0.962413 & 0.966004 & 0.970628 \\
$50-54$ & 0.944839 & 0.948068 & 0.952723 & 0.958805 \\
$55-59$ & 0.919641 & 0.923844 & 0.929845 & 0.937643 \\
$60-64$ & 0.878125 & 0.884239 & 0.892524 & 0.902982 \\
$65-69$ & 0.817252 & 0.825667 & 0.837895 & 0.853936 \\
$70-74$ & 0.743454 & 0.753400 & 0.768674 & 0.789275 \\
$75-79$ & 0.660717 & 0.672260 & 0.689422 & 0.712202 \\
$800 \mathrm{más}$ & 0.410096 & 0.416934 & 0.427622 & 0.442160 \\
\hline
\end{tabular}

FUENTE: Estimaciones del Consejo Nacional de Población con base en las tablas de mortalidad elaboradas por Sergio Camposortega en su tesis de doctorado (1988). 
CUADRO 10. México: estimación del número de inmigrantes internacionales sobrevivientes al final del período de llegada, por intervalos quinquenales de migración, según sexo y grupos de edades 1960-1980. (Estimaciones preliminares).

\begin{tabular}{|c|c|c|c|c|}
\hline \multirow{2}{*}{$\begin{array}{l}\text { Sexo y grupos } \\
\text { de edades }\end{array}$} & \multicolumn{4}{|c|}{ Períodos quinquenales de migración } \\
\hline & $1975-1980$ & $1970-1975$ & $1965-1970$ & $1960-1965$ \\
\hline Total & 511582 & 150385 & 91469 & 44773 \\
\hline Hombres & 323510 & 87494 & 54919 & 27260 \\
\hline $0-4$ & 24704 & 5595 & 2427 & 2140 \\
\hline $5-9$ & 21735 & 5215 & 4705 & 2835 \\
\hline $10-14$ & 14256 & 6423 & 4736 & 2130 \\
\hline $15-19$ & 29810 & 10216 & 5654 & 2374 \\
\hline $20-24$ & 55163 & 11234 & 7364 & 3206 \\
\hline $25-29$ & 46370 & 10433 & 7500 & 3266 \\
\hline $30-34$ & 35659 & 9665 & 6086 & 3204 \\
\hline $35-39$ & 27519 & 7691 & 5222 & 2571 \\
\hline $40-44$ & 20325 & 5916 & 3832 & 1979 \\
\hline $45-49$ & 15763 & 4555 & 3013 & 1268 \\
\hline $50-54$ & 11417 & 3525 & 1815 & 655 \\
\hline $55-59$ & 8687 & 2291 & 918 & 457 \\
\hline $60-64$ & 5863 & 1584 & 599 & 394 \\
\hline $65-69$ & 3024 & 1327 & 497 & 369 \\
\hline $70-74$ & 2035 & 1040 & 316 & 248 \\
\hline $75-79$ & 764 & 486 & 186 & 104 \\
\hline $80-84$ & 324 & 232 & 38 & 47 \\
\hline 85 o más & 92 & 66 & 11 & 13 \\
\hline Mujeres & 188072 & 62891 & 36550 & 17513 \\
\hline $0-4$ & 24332 & 6726 & 2726 & 1509 \\
\hline $5-9$ & 20183 & 5846 & 3345 & 1925 \\
\hline $10-14$ & 13616 & 5150 & 3345 & 1604 \\
\hline $15-19$ & 21896 & 8283 & 5096 & 2170 \\
\hline $20-24$ & 29030 & 8869 & 5673 & 2209 \\
\hline $25-29$ & 23333 & 7405 & 4330 & 1957 \\
\hline $30-34$ & 16181 & 5103 & 3185 & 1589 \\
\hline $35-39$ & 9751 & 3403 & 2260 & 1145 \\
\hline $40-44$ & 6282 & 2522 & 1630 & 823 \\
\hline $45-49$ & 5260 & 2266 & 1276 & 720 \\
\hline $50-54$ & 4195 & 1848 & 990 & 565 \\
\hline $55-59$ & 4004 & 1491 & 909 & 406 \\
\hline $60-64$ & 3431 & 1269 & 691 & 286 \\
\hline $65-69$ & 2594 & 1107 & 427 & 300 \\
\hline $70-74$ & 2049 & 854 & 405 & 165 \\
\hline $75-79$ & 1098 & 326 & 151 & 58 \\
\hline $80-84$ & 594 & 300 & 77 & 57 \\
\hline 85 o más & 243 & 123 & 34 & 25 \\
\hline
\end{tabular}

FUENTE: Cálculos propios con base en información del Censo general de población y vivienda de 1980. INEGI. 
número total de migrantes de retorno sobrevivientes al término de cada uno de los cuatro intervalos de migración (ver cuadro 12), clasificados según sexo y grupos de edad; esta estimación resultó de hacer la diferencia de las respectivas cifras de población contenidas en los cuadros 10 y $11 .^{21}$

Ahora bien, en diversas investigaciones se ha constatado que tanto los trabajadores migratorios mexicanos de retomo, como aquéllos que se encuentran trabajando en Estados Unidos, constituyen una población joven, cuya edad promedio se ubica alrededor de los 30 años, y cerca del $100 \%$ de los individuos que la conforman tienen entre 15 y 54 años de edad. ${ }^{22}$ En base a esta evidencia empirica, se pasó a considerar, para la obtención de las mencionadas estimaciones, los migrantes de retorno de cada período de migración comprendidos en el intervalo de edades 15-54 (ver cuadro 13).

Con auxilio de la clasificación del censo de 1980 y la obtenida a partir de los datos de 1970 respecto al tiempo de residencia en el lugar de empadronamiento correspondiente al total de inmigrantes internacionales y a Ios inmigrantes extranjeros, se distribuyeron los migrantes de retorno de cada sexo de los períodos de migración 1975-1980 y 1965-1970 respectivamente, en los que llegaron en el último año del quinquenio y los que lo hicieron en los cuatro años anteriores. Estas distribuciones se aceptaron como válidas para los migrantes de retomo de edades comprendidas entre 15 y 54 años y se aplicaron a los respectivos totales por sexo del cuadro 13 , obteniendo así los migrantes de

\footnotetext{
${ }^{21}$ En ests forma de cálculo está presente nuevamente el supuesto de que no existe migración intema de extranjeros, o ella es despreciable.

22 "La edad de esta población migrante nos indica que el $48 \%$ del total tenía menos de 30 años, mientras que 3 de cada 4 migrantes tenían menos de 40 años. Esto es, la característica más sobresaliente es que se trata de trabajadores jóvenes en las edades productivas más activas... La edad promedio de esos migrantes W (migrantes de retomo) es de 32.3 años" (Zazueta, 1980:6-7).

"En relación a la edad de la población migrante de trabajadores, ésta nos indica que,..., el $54.7 \%$ del total tenía menos de 30 años de edad... Si lo vemos desde otra perspectiva, tenemos que por cada 10 migrantes casi 8 tenían menos de 40 años de edad. Esta relación es igualmente válida para las mujeres y los hombres" (Zazueta y García y Griego, 1982:52).

"En lo relativo a la variable edad, tenemos que la población tipo V (trabajadores migratorios temporales en Estados Unidos) presenta una estructura joven. Basta decir que entre los 15 y los 29 años se encuentra el $62.4 \%$ del flujo migratorio de ambos sexos; en el grupo de 30 a 49 años de edad se ubica el $30.3 \%$ de esta misma población; y sólo el $7.4 \%$ representa a los migrantes de 50 y más años de edad cumplida" (Zazueta y Corona, 1979:53-54).

"Todas las investigaciones realizadas sobre la población de indocumentados mexicanos han señalado que hay una fuerte concentración de esta población en las edades jóvenes adultas. Entre la población de indocumentados registrados en el censo de Estados Unidos de 1980 ... se observó que el $73 \%$ se encontraba entre las edades de 15 y 44 . Esa misma proporciốn es mayor para la población de trabajadores migratorios. En ambas poblaciones residentes habituales en Estados Unidos y trabajadores migratorios, el promedio de edad de los indocumentados se encuentra entre 25 y 30 años" (García y Griego y Verea, 1988:77-78).
} 
CUADRO 11. México: estimación de número de inmigrantes internacionales extranjeros sobrevivientes al final del período de llegada, por intervalos quinquenales de migración, según sexo y grupos de edades, período 1960-1980 (estimaciones preliminares).

\begin{tabular}{|c|c|c|c|c|}
\hline \multirow{2}{*}{$\begin{array}{l}\text { Sexo y grupos } \\
\text { de edades }\end{array}$} & \multicolumn{4}{|c|}{ Periodos quinquenales de migración } \\
\hline & $1975-1980$ & $1970-1975$ & $1965-1970$ & $1960-1965$ \\
\hline Total & 121690 & 44935 & 36681 & 18104 \\
\hline Hombres & 61949 & 22560 & 18141 & 9154 \\
\hline $0-4$ & 19514 & 5072 & 2245 & 928 \\
\hline $5-9$ & 14541 & 3550 & 1458 & 703 \\
\hline $10-14$ & 5022 & 1370 & 1069 & 529 \\
\hline $15-19$ & 3588 & 1419 & 1356 & 634 \\
\hline $20-24$ & 3920 & 1625 & 1891 & 812 \\
\hline $25-29$ & 3454 & 1541 & 1866 & 888 \\
\hline $30-34$ & 2608 & 1439 & 1650 & 912 \\
\hline $35-39$ & 2046 & 1202 & 1453 & 762 \\
\hline $40-44$ & 1543 & 923 & 1256 & 627 \\
\hline $45-49$ & 1304 & 782 & 1049 & 597 \\
\hline $50-54$ & 1025 & 631 & 825 & 451 \\
\hline $55-59$ & 879 & 595 & 729 & 362 \\
\hline $60-64$ & 771 & 623 & 505 & 346 \\
\hline $65-69$ & 672 & 796 & 360 & 312 \\
\hline $70-74$ & 689 & 672 & 256 & 175 \\
\hline $75-79$ & 278 & 191 & 143 & 69 \\
\hline $80-84$ & 72 & 98 & 23 & 36 \\
\hline 85 o más & 23 & 31 & 7 & 11 \\
\hline Mujeres & 59741 & 22375 & 18540 & 8950 \\
\hline $0-4$ & 19355 & 6294 & 2380 & 999 \\
\hline $5-9$ & 13423 & 3397 & 1309 & 637 \\
\hline $10-14$ & 5403 & 1434 & 1296 & 591 \\
\hline $15-19$ & 4132 & 1660 & 1843 & 808 \\
\hline $20-24$ & 3947 & 1678 & 2082 & 900 \\
\hline $25-29$ & 2940 & 1518 & 1919 & 1010 \\
\hline $30-34$ & 2247 & 1239 & 1617 & 839 \\
\hline $35-39$ & 1605 & 928 & 1371 & 715 \\
\hline $40-44$ & 1162 & 740 & 988 & 558 \\
\hline $45-49$ & 1045 & 738 & 852 & 555 \\
\hline $50-54$ & 927 & 638 & 754 & 458 \\
\hline $55-59$ & 933 & 586 & 738 & 261 \\
\hline $60-64$ & 911 & 501 & 660 & 213 \\
\hline $65-69$ & 694 & 449 & 314 & 168 \\
\hline $70-74$ & 562 & 322 & 219 & 134 \\
\hline $75-79$ & 280 & 90 & 122 & 37 \\
\hline $80-84$ & 112 & 104 & 48 & 42 \\
\hline 85 o más & 63 & 59 & 28 & 25 \\
\hline
\end{tabular}

FUENTE: Cálculos propios con base en información del Censo general de población $y$ vivienda de 1980, INEGI. 
CUADRO 12. Número de migrantes internacionales de retorno sobrevivientes al final del período de llegada, por intervalos quinquenales de migración, según sexo y grupos de edades (1960-1980).

\begin{tabular}{|c|c|c|c|c|}
\hline \multirow{2}{*}{$\begin{array}{l}\text { Sexo y grupos } \\
\text { de edades }\end{array}$} & \multicolumn{4}{|c|}{ Períodos quinquenales de migración } \\
\hline & $1975-1980$ & $1970-1975$ & $1965-1970$ & $1960-1965$ \\
\hline Total & 389892 & 105450 & 54788 & 26669 \\
\hline Hombres & 261561 & 64934 & 36778 & 18106 \\
\hline $0-4$ & 5190 & 523 & 182 & 1212 \\
\hline $5-9$ & 7194 & 1665 & 3247 & 2132 \\
\hline $10-14$ & 9234 & 5053 & 3667 & 1601 \\
\hline $15-19$ & 26222 & 8797 & 4298 & 1740 \\
\hline $20-24$ & 51243 & 9609 & 5473 & 2394 \\
\hline $25-29$ & 42916 & 8892 & 5634 & 2378 \\
\hline $30-34$ & 33051 & 8226 & 4436 & 2292 \\
\hline $35-39$ & 25473 & 6489 & 3769 & 1809 \\
\hline $40-44$ & 18782 & 4993 & 2.576 & 1352 \\
\hline $45-49$ & 14459 & 3773 & 1964 & 671 \\
\hline $50-54$ & 10392 & 2894 & 990 & 204 \\
\hline $55-59$ & 7808 & 1696 & 189 & 95 \\
\hline $60-64$ & 5092 & 961 & 94 & 48 \\
\hline $65-69$ & 2352 & 531 & 137 & 57 \\
\hline $70-74$ & 1346 & 368 & 60 & 73 \\
\hline $75-79$ & 486 & 295 & 43 & 35 \\
\hline $80-84$ & 252 & 134 & 15 & 11 \\
\hline 85 o más & 69 & 35 & 4 & 2 \\
\hline Mujeres & 128331 & 40516 & 18010 & 8563 \\
\hline $0-4$ & 4977 & 432 & 346 & 510 \\
\hline $5-9$ & 6760 & 2449 & 2036 & 1288 \\
\hline $10-14$ & 8213 & 3716 & 2049 & 1013 \\
\hline $15-19$ & 17764 & 6623 & 3253 & 1362 \\
\hline $20-24$ & 25083 & 7191 & 3591 & 1309 \\
\hline $25-29$ & 20393 & 5887 & 2411 & 947 \\
\hline $30-34$ & 13934 & 3864 & 1568 & 750 \\
\hline $35-39$ & 8146 & 2475 & 889 & 430 \\
\hline $40-44$ & 5120 & 1782 & 642 & 265 \\
\hline $45-49$ & 4215 & 1528 & 424 & 165 \\
\hline $50-54$ & 3268 & 1210 & 236 & 107 \\
\hline $55-59$ & 3071 & 905 & 171 & 145 \\
\hline $60-64$ & 2520 & 768 & 31 & 73 \\
\hline $65-69$ & 1900 & 658 & 113 & 132 \\
\hline $70-74$ & 1487 & 532 & 186 & 31 \\
\hline $75-79$ & 818 & 236 & 29 & 21 \\
\hline $80-84$ & 482 & 196 & 29 & 15 \\
\hline 85 o más & 180 & 64 & 6 & 0 \\
\hline
\end{tabular}

FUENTE: Cuadros 10 y 11 . 
retorno de cada sexo de los períodos de migración 1965-1970 y 1975-1980 sobrevivientes al final del mismo, clasificados en los que llegaron en el último año del lustro y los que lo hicieron en el intervalo cuatrianual anterior,

Por otro lado, según los resultados de la Encuesta Nacional de Emigración llevada a cabo por el CENIET, el $90 \%$ de los trabajadores migratorios en México estuvieron en forma indocumentada en Estados Unidos. ${ }^{23}$ Por esta razón, la estimación de los migrantes de retomo indocumentados de edades entre 15 y 54 años se realizó tomando las nueve décimas partes de los totales por sexo del cuadro 13 , asumiéndose que el $10 \%$ restante estuvo trabajando en Estados Unidos con autorización legal, y que en virtud de ello, su salida de México se había producido en un período quinquenal distinto al de regreso. ${ }^{24} \mathrm{Al}$ número total de migrantes de retorno indocumentados de ambos sexos de cada período de migración, ${ }^{25}$ se le aplicó la mencionada tabla de estancia en Estados Unidos, ${ }^{26}$ obteniendo así una estimación del número de migrantes de retorno de cađa intervalo de migración quinquenal que habian emigrado en el mismo lustro, y los que lo habian hecho anteriormente (cuadro 14). La apertura de las estimaciones por sexo y

23 "Entonces, tenemos que al menos 9 de cada 10 migrantes de retomo que fueron entrevistados por la Encuesta Nacional habían trabajado o buscado trabajo en Estados Unidos sin autorización legal para hacerlo" (Zazueta, 1980:22).

24 Este es un supuesto un tanto arbitrario, pero desafortunadamente no se cuenta con estimaciones referidas al tiempo de estancia en Estados Unidos de los trabajadores migratorios mexicanos que estuvieron en aquel país en forma legal.

Se asumió que los migrantes de retomo sobrevivientes al final de cada quinquenio, y clasificados por periodo de migración, llegaron al país en forma uniforme dentro de cada intervalo. Así, los migrantes de los periodos 1970-1975 y 1960-1965 habrian llegado al país distribuidos en cinco partes iguales anuales dentro de cada lustro, admitiendo que su retomo se produjo al 30 de junio de eada año calendario. Para los migrantes de los lustros 75-80 y 65-70 el razonamiento fue análogo. Se supuso que los migrantes que llegaron en el último año del quinquenio lo hicieron a mitad del intervalo (supuesto de uniformidad dentro del año), y los que regresaron en los primeros cuatro años se distribuyeron en partes iguales dentro de cada año y en forma uniforme dentro de ese período, retornando, en promedio, todos a mitad del año en cuestión.

26 Dado que la tabla de estancia en Estados Unidos para trabajadores mexicanos indocumentados que regresaron por cuenta propia estaba preparada para poco más de 3 años de estancia en el vecino país del norte, y a efectos del procedimiento de estimación, era preciso contar con una tabla que se prolongará por lo menos hasta 4 años y medio, fue necesario extrapolar el modelo hasta ese tiempo de estancia. La extrapolación se realizó mediante el ajuste de una función exponencial modificada a los últimos catorce datos contenidos en la tabla. La forma analítica de la función utilizada es:

$g(t)=21,220+\operatorname{EXP}(10.01593-0.00369 * t)$,

donde $\mathrm{t}$ representa el límite inferior del intervalo de estancia de treinta días calendario. El coeficiente de correlación que resultó del ajuste realizado fue r $=0.9999$. 
grupos quinquenales de edades (dentro del rango 15-54) se efectuó en forma proporcional a partir de la distribución del cuadro 13 .

Con este procedimiento fue posible clasificar los migrantes de retorno de cada intervalo en dos categorías:

a) Los migrantes de retorno que habían salido previamente hacia Estados Unidos dentro del mismo quinquenio en que se prodajo su regreso a México y, por tanto, debían ser adicionados directamente en las estimaciones de emigrantes internacionales de cada período.

b) Los migrantes de retomo que se habian desplazado previamente hacia Estados Unidos en un lustro diferente al que se produjo su regreso. Estos migrantes, al inicio de cada período de llegada se encontraban en Estados Unidos ${ }^{27}$ habiendo emigrado hacia aquel país en períodos de migración anteriores. En relación a ellos, fue necesario estimar su número al comienzo de cada intervalo de migración (o lo que es lo mismo, al final del período inmediato anterior), lo cual se llevó a cabo mediante las relaciones de sobrevivencia del cuadro 9; posteriormente, dichas estimaciones se clasificaron por intervalo de migración, en función de las respectivas distribuciones por quinquenio de migración del número total de emigrantes sobrevivientes en 1975, en 1970 y en 1965. Finalmente, las salidas así estimadas de estos migrantes de retorno fueron consideradas también en el cálculo de los emigrantes internacionales de cada lustro.

Por último, es preciso mencionar que las estimaciones definitivas de inmigrantes internacionales que se presentan en el cuadro 18 no corresponden directamente a las cifras del cuadro 10 , sino que en aquéllas se ha tomado en cuenta, como corresponde, la entrada de los emigrantes extranjeros. La estimación de estos últimos forma parte del siguiente capítulo.

\section{ESTIMACIÓN DE LA EMIGRACIÓN INTERNACIONAL}

El procedimiento de estimación de la emigración intemacional tuvo como información básica las estimaciones de Warren y Passel que se presentan en el cuadro 15; éstas corresponden al número de mexicanos residentes en Estados Unidos en 1980, clasificados por período de llegada, sexo y grupos de edades, y son cifras obtenidas luego de corregir los datos del censo norteamericano de aquel año.

$\mathrm{Al}$ analizar el cuadro 15 se puede apreciar que, a efectos de este trabajo, las estimaciones de Warren y Passel contienen algunas restricciones que

27 Se está trabajando con el supuesto de que todos los migrantes de retomo mexicanos habían emigrado previamente hacia Estados Unidos. 
CUADRO 13. México: número de migrantes internacionales de retorno de edades comprendidas entre 15 y 55 años, sobrevivientes al final del período de llegada, por intervalos quinquenales de migración, según sexo y grupos de edades, período 1960-1980.

\begin{tabular}{lrrrr}
\hline \multirow{2}{*}{$\begin{array}{l}\text { Sexo y grupos } \\
\text { de edades }\end{array}$} & \multicolumn{4}{c}{ Períodos quinquenales de migración } \\
& $1975-1980$ & $1970-1975$ & $1965-1970$ & \multicolumn{1}{c}{$1960-1965$} \\
\hline Total & 320461 & 84233 & 42154 & 18175 \\
Hombres & 222538 & 53673 & 29140 & 12840 \\
$15-19$ & 26222 & 8797 & 4298 & 1740 \\
$20-24$ & 51243 & 9609 & 5473 & 2394 \\
$25-29$ & 42916 & 8892 & 5634 & 2378 \\
$30-34$ & 33051 & 8226 & 4436 & 2292 \\
$35-39$ & 25473 & 6489 & 3769 & 1809 \\
$40-44$ & 18782 & 4993 & 2576 & 1352 \\
$45-49$ & 14459 & 3773 & 1964 & 671 \\
$50-54$ & 10392 & 2894 & 990 & 204 \\
Mujeres & 97923 & 30560 & 13014 & 5335 \\
$15-19$ & 17764 & 6623 & 3253 & 1362 \\
$20-24$ & 25083 & 7191 & 3591 & 1309 \\
$25-29$ & 20393 & 5887 & 2411 & 947 \\
$30-34$ & 13934 & 3864 & 1568 & 750 \\
$35-39$ & 8146 & 2475 & 889 & 430 \\
$40-44$ & 5120 & 1782 & 642 & 265 \\
$45-49$ & 4215 & 1528 & 424 & 165 \\
$50-54$ & 3268 & 1210 & 236 & 107 \\
\hline
\end{tabular}

FUENTE: Cuadros 10 y 11.

es preciso levantar. En primer lugar, se engloba a los migrantes del período 1960-1970 en un solo intervalo decenal de llegada y no en dos quinquenales (1960-1965 y 1965-1970) como es nuestra necesidad; y en segundo término, en la distribución por grupos de edades se cuenta solamente con grupos de edades quinquenales hasta el intervalo 40-44, continuando luego con grupos decenales hasta el abierto final "75 o más". En relación a esta información se hace preciso, entonces, estimar el número de mexicanos residentes en Estados Unidos en 1980, llegados a ese país en cada uno de los dos lustros incluidos en el intervalo 1960-1970, y obtener la clasificación completa por grupos quinquenales de edades hasta el abierto final "85 o más". Para ello se recurrió a los datos crudos del censo de población estadounidense de 1980, en el cual está tabulada la población mexicana residente en Estados Unidos por períodos quinquenales de migración hasta 
CUADRO 14. México: número de inmigrantes internacionales de retorno indocumentados en EUA, de edades y sexo comprendidas entre 15 y $\mathbf{5 5}$ años. Sobrevivientes al final del período quinquenal de llegada, por intervalo de migración, según momento en que se produjo la emigración (1960-1980).

\begin{tabular}{lllll}
\hline Tipo de migran- & Períodos quinquenales de migración \\
tes y sexo & $1975-1980$ & $1970-1975$ & $1965-1970$ & $1960-1965$
\end{tabular}

Migrantes de retorno indocumentados de edades

$\begin{array}{lrrrr}\text { 15-54 años } & 288415 & 75810 & 37939 & 16358 \\ \text { Hombres } & 200284 & 48306 & 26226 & 11556 \\ \text { Mujeres } & 88131 & 27504 & 11713 & 4802\end{array}$

Migrantes de retorno que emigraron dentro del mismo quinquenio

$\begin{array}{lrrrr}\text { de regreso } & 136446 & 32696 & 17368 & 7055 \\ \text { Hombres } & 94752 & 20834 & 12006 & 4984 \\ \text { Mujeres } & 41694 & 11862 & 5362 & 2071\end{array}$

Migrantes de retomo que emigraron en quinquenios anteriores

\begin{tabular}{lrrrr} 
al de regreso & 151969 & 43114 & 20571 & 9303 \\
& & & & \\
Hombres & 105532 & 27472 & 14220 & 6572 \\
Mujeres & 46437 & 15642 & 6351 & 2731 \\
\hline
\end{tabular}

FUIENTE: Cuadro 13 y cálculos propios.

1960, según sexo y grupos quinquenales de edades, hasta el grupo abierto final "75 o más" (Partida, 1990). Los migrantes mexicanos del intervalo 1960-1970, estimados por Warren y Passel, fueron distribuidos en los períodos de llegada 1960-1965 y 1965-1970 en forma proporcional a aquellas cifras censales. Después de realizada esta distribución, se pasó a abrir los grupos decenales $45-54,55-64$ y $65-74$, de cada sexo, en los respectivos grupos quinquenales convencionales; en esta ocasión también se realizó la apertura en forma proporcional, en función de la estructura interna de esos grupos de edades determinada por las cifras censales. Finalmente, la distribución del grupo abierto final "75 o más", en los grupos 75-79, 80-84 y 85 o más, se llevó a cabo empleando la técnica de la "ojiva de ejes oblicuos" (Carrier y Farrag, 1961).

A continuación, se procedió a considerar làs estimaciones de mexicanos enumerados en los censos de otros países latinoamericanos 
CUADRO 15. Estimación de mexicanos residentes en estados unidos, sobrevivientes en 1980, por periodo de llegada, según sexo y grupos de edades.

\begin{tabular}{|c|c|c|c|c|c|}
\hline $\begin{array}{l}\text { Sexo y grupos } \\
\text { de edades }\end{array}$ & Total & $1975-1980$ & $\begin{array}{l}\text { Periodo de } \\
1970-1975\end{array}$ & $\begin{array}{l}\text { llegada } \\
1960-1970\end{array}$ & $\begin{array}{c}\text { Antes de } \\
1960\end{array}$ \\
\hline Total hombres & 1319360 & 469878 & 333251 & 281692 & 234539 \\
\hline $0-4$ & 33174 & 33174 & & & \\
\hline $5-9$ & 69838 & 44956 & 24882 & & \\
\hline $10-14$ & 87803 & 39284 & 32799 & 15720 & \\
\hline $15-19$ & 135946 & 72306 & 32518 & 31122 & \\
\hline $20-24$ & 207664 & 111552 & 54494 & 32834 & 8784 \\
\hline $25-29$ & 196420 & 70016 & 72382 & 39807 & 14215 \\
\hline $30-34$ & 149677 & 39462 & 49239 & 45942 & 15034 \\
\hline $35-39$ & 104018 & 21712 & 28186 & 37435 & 16685 \\
\hline $40-44$ & 79707 & 14024 & 16338 & 30128 & 19217 \\
\hline $45-54$ & 103953 & 14506 & 13849 & 29751 & 45847 \\
\hline $55-64$ & 71462 & 6023 & 5473 & 12976 & 46990 \\
\hline $65-74$ & 47517 & 2010 & 1952 & 4356 & 39199 \\
\hline 75 o más & 32181 & 853 & 1139 & 1621 & 28568 \\
\hline Total mujeres & 1211463 & 383778 & 299870 & 282748 & 245067 \\
\hline $0-4$ & 32015 & 32015 & & & \\
\hline $5-9$ & 66032 & 42821 & 23211 & & \\
\hline $10-14$ & 87969 & 38445 & 34015 & 15509 & \\
\hline $15-19$ & 115206 & 54133 & 31880 & 29193 & \\
\hline $20-24$ & 160991 & 75971 & 45436 & 31917 & 7667 \\
\hline $25-29$ & 158020 & 51857 & 56227 & 36627 & 13309 \\
\hline $30-34$ & 132639 & 31910 & 41333 & 43420 & 15976 \\
\hline $35-39$ & 99263 & 17635 & 24492 & 39210 & 17926 \\
\hline $40-44$ & 76649 & 11573 & 14251 & 29219 & 21606 \\
\hline $45-54$ & 109599 & 14536 & 16886 & 33199 & 44978 \\
\hline $55-64$ & 70149 & 7505 & 7155 & 14462 & 41027 \\
\hline $65-74$ & 60353 & 3512 & 3416 & 6694 & 46731 \\
\hline 75 o más & 42578 & 1865 & 1568 & 3298 & 35847 \\
\hline
\end{tabular}

FUENTE: "A Count of the Uncountable: Estimates of the Undocumented Aliens Counted in the 1980 United States Census". J. Warren R. y Passel. 1987. Demography. 
alrededor de 1980, derivadas del proyecto IMILA (CELADE, 1989), A partir de esta información, se tuvo conocimiento de la existencia de poco más de 35 mil mexicanos de ambos sexos (ver cuadro 16), contabilizados en aquellos países de América Latina que levantaron censos alrededor de 1980 (se incluye también información de España, Bẻlgica, Canadá y Alemania).

En virtud de la falta de otro tipo de informaciốn adicional, se optó por distribuir este número de emigrantes, por sexo, edad y período de migración, en forma proporcional a partir de las cifras corregidas (de acuerdo al tratamiento anterior) sobre los mexicanos residentes en Estados Unidos en 1980. Luego de esta distribución, las nuevas estimaciones de emigrantes mexicanos en Latinoamérica fueron adicionados a las respectivas estimaciones de emigrantes mexicanos en Estados Unidos. Subsiguientemente, con auxilio de las relaciones de sobreviviencia representativas de la mortalidad de cada lustro, y a partir de las estimaciones de emigrantes mexicanos sobrevivientes en 1980 clasificadas por intervalos quinquenales de migración, sexo y edad, se obtuvo el número de emigrantes de cada quinquenio sobrevivientes al final del período.

La siguiente etapa consistió en la estimación de la emigración internacional de extranjeros. Para el intervalo 1975-1980, la estimación por sexo y grupos de edades provino directamente del censo de población estadounidense (Partida, 1990). En este caso se consideraron como emigrantes extranjeros del periodo a aquellas personas no mexicanas residentes en Estados Unidos a la fecha del censo, cuyo lugar de residencia cinco años antes había sido México (ver cuađro 17). Las estimaciones para los otros tres períodos quinquenales de migración se dedujeron retroproyectando la población nacida en el exterior enumerada en el censo mexicano de 1980 (tomando en cuenta la mortalidad de cada lustro y la entrada de extranjeros), y comparándola, posteriormente, con la contabilizada según los levantamientos censales de 1970 y $1960 .^{28}$ De esta forma se estimaron los emigrantes extranjeros sobrevivientes en el exterior, al término de cada uno de los cuatro invervalos quinquenales de migración.

Al principio de cada lustro de migración, estos extranjeros se encontraban en México, y por el hecho de haber nacido en el exterior debieron haber llegado al país en un fecha anterior a aquel momento. Es menester

${ }^{28} \mathrm{La}$ distribución de los emigrantes extranjeros del decenio 1960-1970 en los períodos quinquenales 1960-1965 y 1965-1970, se efectú en forma proporcional a la distribución de los emigrantes nacidos en el exteríor del intervalo 1970-1980. 
CUADRO 16. México: población nacida en México y censada en otros paises alrededor de 1980.

\begin{tabular}{lrr}
\hline País de presencia & Año censal & Población \\
\hline Total & & 35228 \\
Argentinà & 1980 & 966 \\
Bolivia & 1976 & 5176 \\
Brasil & 1980 & 853 \\
Costa Rica & 1984 & 1276 \\
Chile & 1982 & 376 \\
Ecuador & 1982 & 494 \\
Guatemala & 1981 & 2977 \\
Panamá & 1980 & 1060 \\
Paraguay & 1982 & 3170 \\
Perú & 1981 & 641 \\
Venezuela & 1981 & 2749 \\
España* & 1980 & 1909 \\
Bélgica & 1981 & 217 \\
Canadá & 1981 & 10980 \\
Rep. Fed. de Alemania & 1984 & 2384 \\
\hline
\end{tabular}

FUENTE: CELADE (1989).

entonces estimar el período de llegada a la república mexicana de aquellos emigrantes extranjeros, para que sean considerados en las estimaciones correspondientes de inmigrantes internacionales. La ubicación en el tiempo de la llegada de los emigrantes nacidos en el exterior se realizó a partir de las respectivas distribuciones por período de migración, del número total de inmigrantes extranjeros sobrevivientes en 1975, en 1970 y en 1965.

Por último, con las cifras de emigrantes internacionales mexicanos de la primera parte, las estimaciones de emigrantes extranjeros obtenidas previamente y las salidas correspondientes a los migrantes de retorno del capítulo anterior, se obtuvieron las estimaciones finales de emigrantes 
CUADRO 17. Número de personas no mexicanas residentes en Estados Unidos en 1980 y que residian en México en 1975 , por sexo y grupos de edades.

\begin{tabular}{lrrr}
\hline Grupos de edades & Total & Hombres & Mujeres \\
\hline Total & 62679 & 32524 & 30155 \\
$5-9$ & 13637 & 6873 & 6764 \\
$10-14$ & 7213 & 3762 & 3451 \\
$15-19$ & 6990 & 3611 & 3379 \\
$20-24$ & 8104 & 4148 & 3956 \\
$25-29$ & 7701 & 4321 & 3380 \\
$30-34$ & 5636 & 2770 & 2866 \\
$35-39$ & 3240 & 1776 & 1464 \\
$40-44$ & 1996 & 1050 & 946 \\
$45-49$ & 1675 & 882 & 793 \\
$50-54$ & 1835 & 881 & 954 \\
$55-59$ & 1694 & 850 & 844 \\
$60-64$ & 904 & 473 & 431 \\
$65-69$ & 785 & 419 & 366 \\
$70-74$ & 677 & 351 & 326 \\
$75-79$ & 342 & 203 & 139 \\
$80-84$ & 241 & 102 & 68 \\
850 más & 120 & 52 & 28 \\
& & &
\end{tabular}

FUENIE: Partida, Virgilio. 1990.

NOTA: La apertura del grupo abierto final "75 o más" en dos grupos quinquenales y el abierto final "85 o más", se realizó utilizando el procedimiento de la ojiva de ejes oblicuos.

internacionales para cada uno de los cuatro períodos quinquenales de migración, calculadas al término de cada intervalo y clasificadas por sexo y grupos de edades (ver cuadro 19 ).

En el cuadro 20 se presentan las estimaciones del saldo neto migratorio para cada período, las cuales resultaron de la suma algebraica de las cifras respectivas de inmigrantes y emigrantes. 
CUADRO 18. México: estimación del número de inmigrantes internacionales sobrevivientes al final del período de llegada, por intervalos quinquenales de migración, según sexo y grupos de edades (1960-1980).

\begin{tabular}{|c|c|c|c|c|}
\hline \multirow{2}{*}{$\begin{array}{l}\text { Sexo y grupos } \\
\text { de edades }\end{array}$} & \multicolumn{4}{|c|}{ Períodos quinquenales de migración } \\
\hline & $1975-1980$ & $1970-1975$ & $1965-1970$ & $1960-1965$ \\
\hline Total & 511582 & 181145 & 126297 & 108372 \\
\hline Total hombres & 323510 & 103554 & 73050 & 61180 \\
\hline $0-4$ & 24704 & 12574 & 7687 & 15441 \\
\hline $5-9$ & 21735 & 7553 & 7399 & 8341 \\
\hline $10-14$ & 14256 & 7764 & 6892 & 5446 \\
\hline $15-19$ & 29810 & 11844 & 8079 & 5885 \\
\hline $20-24$ & 55163 & 12845 & 9633 & 6586 \\
\hline $25-29$ & 46370 & 11281 & 8797 & 5068 \\
\hline $30-34$ & 35659 & 10138 & 6729 & 4248 \\
\hline $35-39$ & 27519 & 7912 & 5607 & 3101 \\
\hline 40-44 & 20) 325 & 6057 & 4134 & 2347 \\
\hline $45-49$ & 15763 & 4673 & 3262 & 1566 \\
\hline $50-54$ & 11417 & 3619 & 1956 & 863 \\
\hline $55-59$ & 8687 & 2342 & 1017 & 597 \\
\hline $60-64$ & 5863 & 1637 & 677 & 536 \\
\hline $65-69$ & 3024 & 1402 & 550 & 553 \\
\hline $70-74$ & 2035 & 1094 & 363 & 352 \\
\hline $75-79$ & 764 & 505 & 213 & 152 \\
\hline $80-84$ & 324 & 244 & 43 & 74 \\
\hline 85 o más & 92 & 70 & 12 & 24 \\
\hline Total mujeres & 188072 & 77591 & 53247 & 47192 \\
\hline $0-4$ & 24332 & 13590 & 7815 & 14628 \\
\hline $5-9$ & 20183 & 7903 & 5603 & 6197 \\
\hline $10-14$ & 13616 & 6465 & 5569 & 4495 \\
\hline $15-19$ & 21896 & 9902 & 7487 & 5558 \\
\hline $20-24$ & 29030 & 10001 & 7673 & 4444 \\
\hline $25-29$ & 23333 & 8193 & 5416 & 3523 \\
\hline $30-34$ & 16181 & 5409 & 3670 & 2241 \\
\hline $35-39$ & 9751 & 3546 & 2560 & 1545 \\
\hline $40-44$ & 6282 & 2617 & 1858 & 1106 \\
\hline $45-49$ & 5260 & 2381 & 1478 & 993 \\
\hline $50-54$ & 4195 & 1940 & 1113 & 776 \\
\hline $55-59$ & 4004 & 1537 & 1005 & 509 \\
\hline $60-64$ & 3431 & 1309 & 797 & 385 \\
\hline $65-69$ & 2594 & 1153 & 480 & 398 \\
\hline $70-74$ & 2049 & 879 & 438 & 220 \\
\hline $75-79$ & 1098 & 333 & 165 & 74 \\
\hline $80-84$ & 594 & 306 & 85 & 69 \\
\hline 85 o más & 243 & 127 & 35 & 31 \\
\hline
\end{tabular}

FUENTE: Cálculos propios. 
CUADRO 19. México: estimación del número de emigrantes internacionales sobrevivientes al final del período de llegada, por intervalos quinquenales de migración, según sexo y grupos de edades (1960-1980).

\begin{tabular}{|c|c|c|c|c|}
\hline \multirow{2}{*}{$\begin{array}{l}\text { Sexo y grupos } \\
\text { de edades }\end{array}$} & \multicolumn{4}{|c|}{ Períodos quinquenales de migración } \\
\hline & $1975-1980$ & $1970-1975$ & $1965-1970$ & $1960-1965$ \\
\hline Total & 1074835 & 833120 & 565582 & 388224 \\
\hline Total hombres & 608887 & 457275 & 302844 & 210079 \\
\hline $0-4$ & 38826 & 33442 & 21349 & 20905 \\
\hline $5-9$ & 52455 & 43412 & 38736 & 30536 \\
\hline $10-14$ & 43593 & 42987 & 34054 & 22419 \\
\hline $15-19$ & 88088 & 78323 & 45286 & 23131 \\
\hline $20-24$ & 139072 & 95250 & 53880 & 27045 \\
\hline $25-29$ & 93585 & 65555 & 40694 & 28732 \\
\hline $30-34$ & 56853 & 39145 & 25155 & 20017 \\
\hline $35-39$ & 34636 & 23310 & 14275 & 12570 \\
\hline $40-44$ & 23266 & 13376 & 8759 & 10282 \\
\hline $45-49$ & 16033 & 8026 & 6607 & 4983 \\
\hline $50-54$ & 11019 & 6133 & 4802 & 3273 \\
\hline $55-59$ & 4853 & 3071 & 3482 & 2188 \\
\hline $60-64$ & 2577 & 1888 & 2015 & 1404 \\
\hline $65-69$ & 1613 & 1101 & 1499 & 1108 \\
\hline $70-74$ & 1195 & 937 & 1102 & 716 \\
\hline $75-79$ & 616 & 632 & 602 & 396 \\
\hline $80-84$ & 362 & 401 & 339 & 228 \\
\hline 85 o más & 245 & 286 & 208 & 146 \\
\hline Total mujeres & 465948 & 375845 & 262738 & 178145 \\
\hline $0-4$ & 37438 & 31175 & 21644 & 17795 \\
\hline $5-9$ & 50181 & 43867 & 34379 & 25730 \\
\hline $10-14$ & 42431 & 39633 & 28665 & 19784 \\
\hline $15-19$ & 65830 & 58465 & 36277 & 20309 \\
\hline $20-24$ & 91665 & 68637 & 43450 & 24897 \\
\hline $25-29$ & 64642 & 49754 & 31375 & 21372 \\
\hline $30-34$ & 41153 & 29622 & 20872 & 15488 \\
\hline $35-39$ & 22813 & 17099 & 13240 & 9479 \\
\hline $40-44$ & 14860 & 11914 & 9055 & 6434 \\
\hline $45-49$ & 10740 & 8638 & 6753 & 4811 \\
\hline $50-54$ & 8931 & 6267 & 5091 & 3604 \\
\hline $55-59$ & 5427 & 3451 & 3947 & 3102 \\
\hline $60-64$ & 3458 & 2787 & 2462 & 1926 \\
\hline $65-69$ & 2562 & 1783 & 1959 & 1401 \\
\hline $70-74$ & 1691 & 1211 & 1577 & 876 \\
\hline $75-79$ & 959 & 799 & 1047 & 607 \\
\hline $80-84$ & 736 & 468 & 610 & 339 \\
\hline 85 o más & 431 & 275 & 335 & 191 \\
\hline
\end{tabular}

FUENTE: Cálculos propios. 
CUADRO 20. México: estimación de la migración neta internacional calculada al final de cada período de migración, por intervalos quinquenales de migración, según sexo y grupos de edades (1960-1980).

\begin{tabular}{|c|c|c|c|c|}
\hline \multirow{2}{*}{$\begin{array}{l}\text { Sexo y grupos } \\
\text { de edades }\end{array}$} & \multicolumn{4}{|c|}{ Períodos quinquenales de migración } \\
\hline & $1975-1980$ & $1970-1975$ & $1965-1970$ & $1960-1965$ \\
\hline Total & $(563253)$ & (651975) & (439 285) & $(279852)$ \\
\hline Total hombres & $(285377)$ & $(353721)$ & $(229794)$ & (148 899) \\
\hline $0-4$ & (14 122) & $(20868)$ & (13 662) & (5 464) \\
\hline $5-9$ & $(30720)$ & $(35859)$ & (31 337) & (22 195) \\
\hline $10-14$ & $(29337)$ & $(35223)$ & $(27162)$ & (16973) \\
\hline $15-19$ & $(58278)$ & $(66479)$ & (37 207) & (17 246) \\
\hline $20-24$ & $(83909)$ & $(82405)$ & $(44247)$ & $(20459)$ \\
\hline $25-29$ & $(47215)$ & $(54274)$ & $(31897)$ & $(23664)$ \\
\hline $30-34$ & (21 194) & $(29007)$ & $(18426)$ & (15 769) \\
\hline $35-39$ & $(7117)$ & (15398) & $(8668)$ & (9 469) \\
\hline $40-44$ & (2941) & (7319) & $(4625)$ & (7935) \\
\hline $45-49$ & $(270)$ & (3353) & (3345) & $(3417)$ \\
\hline $50-54$ & 398 & $(2514)$ & $(2846)$ & $(2410)$ \\
\hline $55-59$ & 3834 & $(729)$ & $(2465)$ & (1591) \\
\hline $60-64$ & 3286 & (251) & (1 338$)$ & $(868)$ \\
\hline 65.69 & 1411 & 301 & (949) & (555) \\
\hline $70-74$ & 840 & 157 & (739) & (364) \\
\hline $75-79$ & 148 & (127) & (389) & (244) \\
\hline $80-84$ & (38) & (157) & (296) & (154) \\
\hline 85 o más & (153) & (216) & (196) & (122) \\
\hline Total mujeres & (277876) & (298 254) & (209 491) & (130953) \\
\hline $0-4$ & $(13106)$ & $(17585)$ & $(13829)$ & (3 167) \\
\hline $5-9$ & (29 998) & $(35964)$ & $(28776)$ & (19 533) \\
\hline $10-14$ & (28 815) & $\left(\begin{array}{lll}33 & 168\end{array}\right)$ & (23096) & (15 289) \\
\hline $15-19$ & (43 934) & (48563) & $(28790)$ & (14 751) \\
\hline $20-24$ & (62 635) & $(58636)$ & (35 777) & (20453) \\
\hline $25-29$ & $(41309)$ & $(41561)$ & $(25959)$ & (17 849) \\
\hline $30-34$ & (24972) & $(24213)$ & (17 202) & (13247) \\
\hline $35-39$ & $(13062)$ & $(13553)$ & (10 680) & $(7934)$ \\
\hline $40-44$ & (8578) & (9 297) & (7 197) & $(5328)$ \\
\hline $45-49$ & $(5480)$ & $(6257)$ & $(5275)$ & (3818) \\
\hline $50-54$ & (4 736) & (4 327) & (3978) & $(2828)$ \\
\hline $55-59$ & (1 423) & (1914) & (2942) & (2593) \\
\hline $60-64$ & (27) & (1478) & (1 665) & (1541) \\
\hline $65-69$ & 32 & (630) & (1479) & $(1003)$ \\
\hline $70-74$ & 358 & (332) & (1 139) & (656) \\
\hline $75-79$ & 139 & $(466)$ & $(882)$ & (533) \\
\hline $80-84$ & (142) & (162) & (525) & (270) \\
\hline 85 o más & (188) & (148) & $(300)$ & (160) \\
\hline
\end{tabular}

FUENTE: Cálculos propios. 


\section{CONSIDERACIONES FINALES}

A manera de conclusión, cabe mencionar dos aspectos interesantes que se pueden apreciar al analizar las estimaciones resultantes:

a) El descenso, en valor absoluto, de los volúmenes estimados para cada sexo de la migración neta del periodo 1975-1980, en comparación a las cifras del intervalo de migración inmediato anterior. Este hecho tiene su explicación no en una posible disminución de la emigración "definitiva", la cual, por otra parte, continúa aumentando, sino en un importante incremento de la migración de retorno de Estados Unidos durante el último lustro de migración considerado. Una migración de retorno que está conformada por dos tipos de migrantes: los que habían salido del país en quinquenios anteriores y los que lo habian hecho dentro del mismo intervalo de migración. Es pertinente también tener en cuenta que este incremento en la migración de retorno del último período puede explicarse, en alguna medida, por el efecto que produce el hecho de que la información básica sobre la migración de entrada está referida al último movimiento realizado y proviene de un recuento censal llevado a cabo al final del intervalo (Arévalo, 1985).

b) El cambio de signo en el saldo migratorio de algunos grupos de edades avanzadas, especialmente en los hombres dentro del período de migración 1975-1980. La explicación de esto tiene también como argumentación principal el importante volumen de migrantes de retorno que en ese período regresaron de los Estados Unidos. En esta ocasión, serían hombres que regresan a México luego de haber estado trabajando varios años en el vecino país del norte y que, conjuntamente con la entrada de otros extranjeros, hacen que los ingresos al país en esos grupos de edades sean mayores que las salidas.

Finalmente, en el proceso de estimación que se describe en este documento se han utilizado, como ya se ha mencionado, dos fuentes diferentes de información. En los datos que estas fuentes nos brindan se pueden identificar dos tipos de migrantes cualitativamente diferentes: los migrantes "definitivos" y los migrantes temporales. Los primeros son los que han trasladado su residencia habitual para pasar a vivir en forma más o menos permanente en el exterior; dentro de esta categoría se ubican los mexicanos que residen en Estados Unidos o los extranjeros que viven en México. Los migrantes temporales (también llamados migrantes laborales), en cambio, no trasladan su lugar de residencia habitual, sino que se desplazan a otro país - generalmente limítrofe-por espacios reducidos (habitualmente menos de un año) para desempeñar algún trabajo zafral o temporal; en este caso se encuentran una buena parte de los migrantes de 
retorno mexicanos, es decir, aquellos migrantes que han permanecido trabajando por lo menos 6 meses en Estados Unidos, pero cuyo lugar de residencia habitual y todos sus familiares, estuvieron ubicados siempre en México.

Si se pretendiera realizar un estudio más estructural de la migración internacional y de los componentes que conforman este fenómeno, considerando variables sociales y económicas, la diferenciación analítica entre migrantes "definitivos" y temporales sería de suma importancia y en algún sentido imprescindible. Sin embargo, en este trabajo esa diferencia cualitativa no es demasiado trascendente, puesto que el objetivo de este estudio consiste en obtener una estimación del número de movimientos de entrada y salida ocurridos en cada intervalo y su balance final. Por esta razón, en el caso de las salidas internacionales se tomaron en cuenta aquellos movimientos que involucraron un traslado de la residencia habitual $y$, para el caso de los migrantes de retorno, una permanencia mayor a 6 meses en el país de destino. En el caso de las entradas, se consideraron los extranjeros residentes habituales en México y los migrantes mexicanos de retorno que hubieran estado fuera por lo menos 6 meses.

\section{BIBLIOGRAFIA}

ARÉVALO, Jorge. 1985. "Problemas de la medición de la migración interna". En: Los Censos de Población del 80. Taller de Análisis y Evaluación. INDEC/CELADE. Buenos Aires, Argentina, 1985.

CAMPOSORTEGA, S. 1988. "L'analyse demographique de la morkalité au Mexique, 1940-1980". Tesis de doctorado en Demografía presentada en el Instituto de Demografía de la Universidad Católica de Lovaina.

CARRIER, N.H. y Farrag, A.M. 1961. "La reducción de errores en los censos de población para los páses estadísticamente subdesarrollados". Revista Estadistica. Journal of the Inter American Statistical Institute, no. 71.

CELADE. 1989. "Investigación de la migración internacional en Latinoamérica". Boletín Demográfico, no, 43. CELADE, Santiago, Chile.

CERVERA, Miguel, 1979. Tabla de estancia en Estados Unidos para trabajadores mexicanos indocumentados, STPS, CENIET, México, D.F.

CHACKIEL, J. y Macció, G. 1978. Evaluación y corrección de datos demograficos. CELADE. Serie B, no.39, Santiago, Chile.

CONAPO. 1989. "Proyecciones de la población de México, 1980-2025". México, D.F. 
CORONA, Rodolfo. 1986. Evaluación de los datos censales de 1980. Población residente y migración en Baja California. CEFNOMEX. Baja California, México.

- 1988. Evaluación conceptual y numérica de la información sobre migración del censo de población de 1980. Aportes de investigación. No. 24. UNAM. México.

DIRECCIÓN GENERAL DE ESTADÍSTICA (DGE). 1962. VIII Censo General de Poblacion, 1960. Resumen General, SIC, México.

- 1972. Ix Censo General de Población y Vivienda, 1970. Resumen General. SIC, México.

- S/f. Manual del empadronador: X Censo General de Población y Vivienda, 1980. SPP. DGI. México.

GARCÍA Y GRIEGO, M. y Verea, M. 1988. "Migración de trabajadores mexicanos a Estados Unidos". México y Estados Unidos frente a la migración de indocumentados. Coordinación de Humanidades, UNAM, Porrúa. México.

HAM, R. y Bustamante, J. 1979. "Las expulsiones de indocumentados mexicanos". Demografía y Economía. Vol. XII, no. 2, El Colegio de México. México.

HILL, Ken. 1979. "Estimación de la emigración por edades a partir de la información sobre residencia de hermanos". Nolas de población, Año VII, no. 21. CELADE. Santiago, Chile.

INEGI. 1986. X Censo General de Población y Vivienda, 1980, Resumen General, Volumen II. México.

JASPERS, Dirk. 1987. "Algunas notas sobre la estimación de la migración internacional". Notas de población. Año XV, no. 43, CELADE, Santiago, Chile.

LÓPEZ CASTRO, Gustavo. 1986. La casa dividida: un estudio de caso sobre la migración a Estados Unidos en un pueblo michoacano. El Colegio de Michoacán y Asociación Mexicana de Población, México.

MARTÍNEZ, G. y Bustamante, J. 1978. La segunda encuesta a trabajadores no documentados devueltos de los Estados Unidos de agosto de 1978: segunda elapa del programa de investigación de la Encuesta Nacional de Emigración a la Frontera Norte del país y a los Estados Unidos. STPS, CENIET, Guadalajara, México.

MORALES,Patricia. 1989. Indocumentados mexicanos: causas y razones de la migración laboral. Grijalbo, México, D.F.

NACIONES UNIDAS, 1972, Manual vl. Métodos de medición de la migración interna. Estudios de población no. 47, ST/SOA/Serie A/47. Naciones Unidas, Nueva York. 
- 1975. "Manual VIII. Métodos para hacer proyecciones de la población urbana y rural". Estudios de la Población. No.55, ST/ESA/SER,A/55. Naciones Unidas, Nueva York.

PARTIDA, Virgilio. 1990. "Estimación de la migración internacional mexicana 1960-1980". Ponencia presentada en el Seminario de Análisis y Evaluación de Datos de Población. INEGI. México.

PUJOL, José M. 1988. Proyecciones de población a nivel nacional: método de los componentes". CELADE. Santiago, Chile. Inédito.

RINCÓN, Manuel J, 1984. "Conciliación censal y determinación de la población base". Mélodos paraProyecciones Demográficas. CELA$\mathrm{DE}$, serie E, no.1003. Costa Rica.

SOMOZA, Jorge. 1977. "Una idea para estimar la población migrante por sexo y edad en el censo de un país". Notas de población. Año v, no.15. CELADE, Santiago, Chile.

TUIRÁN, Rodolfo. 1984, "El volumen de la inmigraciónmexicana indocumentada en los Estados Unidos: especulación vs. conocimiento científico", Los factores del cambio demográfico en México. René Jiménez y Alberto Minujín, comps. UNAM. Siglo XXI Editores. México.

VEREA, Mónica. 1988. Contradicciones de la ley Simpson Rodino en México y Estados Unidos frente a la migración de los indocumenlados. Coordinación de Humanidades, UNAM. Porrúa, México.

WARREN, R. y Passel. J. 1987. "A Count of the Uncontable: Estimates of the Undocumented Aliens Counted in the 1980 United States Census", Demography, 24(3).

ZABA, Basia. 1986. Measurement of Emigration Using Indirect Techniques, Manual for the Collection and Analysis of Data on Residence of Relatives. Ordina Editions. Liege, Belgique.

ZAZUETA, Carlos. 1980. Trabajadores migrantes de retorno en México: algunos resultados preliminares, STPS, CENIET. México, D.F.

ZAZUETA, C. y Corona, R. 1979. Los trabajadores mexicanos en Estados Unidos: primeros resultados de la Encuesta Nacional de Emigración (diciembre 1978-enero 1979). STPS, CENIET, México.

ZAZUETA, C, y García y Griego, M. 1982. Los trabajadores mexicanos en Estados Unidos: resultados de la Encuesta Nacional de Emigración a la Frontera Norte del País y a los Estados Unidos. STPS, CENIET, México, D.F. 